\title{
Estudio geológico de la cavidad de Praileaitz I (Deba,Gipuzkoa)
}

\author{
Praileaitz I (Deba,Gipuzkoa) haitzuloaren ikerketa geologikoa \\ Geological Survey of Praileaitz I cavity (Deba, Gipuzkoa)
}

PALABRAS CLAVE: Geomorfología, Sedimentos endokársticos, Paleoclima.

GAKO-HITZAK: Geomorfologia, Sedimentu endokarstikoak, Paleoklima.

KEYWORDS: Geomorphology, Endokarstic sediments, Paleoclimate.

\begin{abstract}
Arantxa ARANBURU(1,2), Martin ARRIOLABENGOA ${ }^{(1,2)}$, Eneko IRIARTE(2,3), Iñaki VADILLO(4), Pablo ARESO(5), Ana URIZ ${ }^{(5)}$
\section{RESUMEN}

La cueva de Praileaitz I, situada en la localidad de Deba (Gipuzkoa), es uno de los pocos enclaves del País Vasco donde se conservan restos de pinturas rupestres. Por este motivo, ha sido considerada zona de máxima protección. El estudio geológico del interior de la cavidad y de su entorno, así como de los procesos que acontecen en su entorno, son importantes para implementar los mejores medios de conservación. La localización de la entrada de la cueva en un frente de cantera y los rasgos de degradación que muestran los espeleotemas contribuyen a que la actuación para conservar la cavidad sea de especial importancia. En el presente trabajo se presenta un estudio geomorfológico, tanto de la cueva como del entorno, y un análisis de los diferentes sedimentos, detríticos y químicos, que se encuentran en su interior con el objetivo de interpretar el paleoclima.
\end{abstract}

\section{LABURPENA}

Debako udalerrian (Gipuzkoa) kokatzen den Praileaitz I kobazuloa, antzinako pinturak dituen bakarretarikoa da Euskal Herrian, eta ondorioz babesturiko gune gisa kontsideratu da. Pinturen kontserbazioa zuztartzeko garrantzitsua da kobazuloaren kanpoaldeko eta barnealdeko ikerketa geologikoa burutzea, zein bere inguruan ematen diren prozesuen karakterizazioa egitea. Koba sarrera harrobi baten frentean aurkiturik eta pinturak aurkitzen diren espeleotemen degradazio maila ikusirik, berauek babesteko burutu beharreko ikerketak garrantzi handia hartzen dute. Lan honen bitartez, koba barneko eta inguruko ikerketa geomorfologikoa eskaintzen da, berau osatzen duten sedimentu ezberdinen analisiekin batera.

\section{ABSTRACT}

The Praileaitz I Cave, located in the town of Deba (Gipuzkoa), corresponds to one of the few enclaves of the Basque Country where cave paintings are preserved. For this reason, it has been considered the establishment of a maximum protection zone. The geological studies of the cavity and its surroundings, as well as the processes that occur in the environment, are decisive to determine the best means of preservation. The location of the entrance to the cave in a quarry front and features of the speleothems showing degradation, make action to preserve the cavity is of special importance. The present work presents a geomorphologic study of both the cave and its environment, and analyses of different sediment fill it.

\section{1.- INTRODUCCIÓN Y OBJETIVOS}

Durante el Cuaternario el territorio que actualmente corresponde al País Vasco ejercía como corredor natural de obligado tránsito entre el continente europeo y la Península lbérica. Por ello, gran parte de las cavidades de la zona presentan un rico registro arqueológico que, sin embargo, no se refleja en la cantidad de pinturas conservadas. La cueva de Praileaitz I es uno de esos escasos puntos que albergan pinturas rupestres por lo que se ha declarado QCP (Qualified Cultural Property) en el 2006, según el decreto 7/90 del País Vasco (BOPV, 157, 6 de agosto de 1990). Esta condición implica la existencia de una zona de máxima protección; para ello es necesario conocer los aspectos más significativos de la cueva de Praileaitz I desde diferentes especialidades: geología estructural, geofísica, hidrología, geomorfología, estratigrafía y petrología. Estos estudios son de especial rele-

\footnotetext{
(1) Dpto. Mineralogía y Petrología. Facultad de Ciencia y Tecnología, UPV/EHU. 48940 Leioa arantza.aranburu@ehu.es.

(2) Geo-Q Aranzadi. Kortesanabarri Baserria, Mendibile Kalea, 48940 Leioa

(3) Laboratorio de Evolución Humana, Dpto de Ciencias Históricas y Geografía, Universidad de Burgos. Plaza de Misael Bañuelos s/n, 09001, Burgos

(4) Dpto. de Ecología y Geología, Universidad de Málaga, Avda. Cervantes, 229071 Málaga

(5) Sociedad de Ciencias Aranzadi. Zorroagagaina, 11, 20014 Donostia - San Sebastián
} 

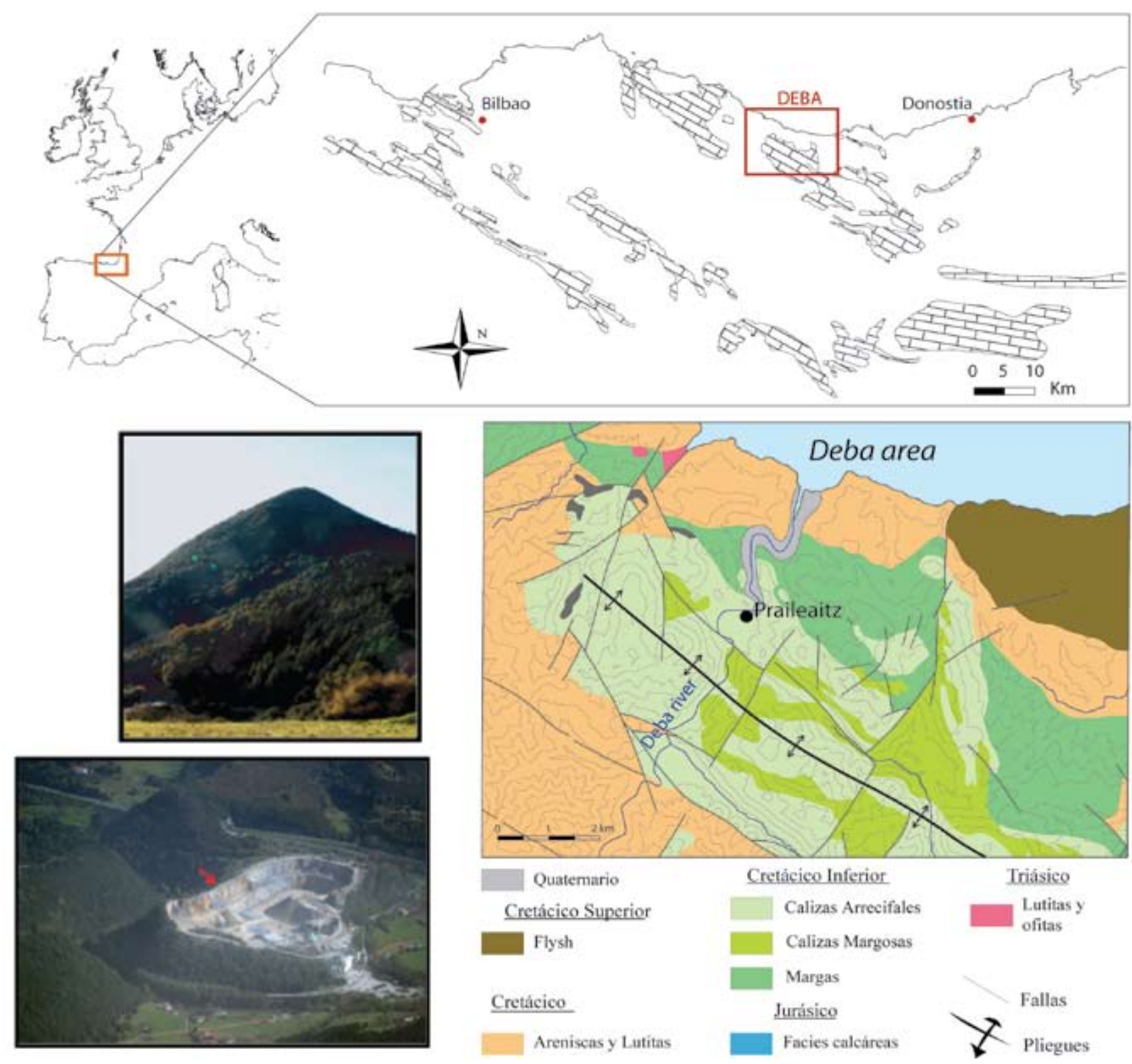

Fig. 1. Mapa geológico del entorno de la Cueva de Praileaitz I. La flecha roja de fotografía indica la localización de la cueva (modificado de ARANBURU et al., 2015). / Location of Praileaitz Cave I (red arrow) and geological map of the area (modified from ARANBURU et al., 2015).

vancia debido a que la entrada de la cueva se localiza en el frente de una cantera (Fig. 1b) que supone una amenaza directa; además, se ha comprobado cómo los espeleotemas presentes sufren varias patologías que los degradan.

El objetivo de este trabajo es presentar los rasgos que describen la cavidad de Praileaitz I, es decir, la geología de la cueva y las fases de relleno que presentan las diferentes salas, para que sirva de encuadre de futuros trabajos enfocados a la conservación del sistema kárstico y de los restos arqueológicos que guarda. Con esta perspectiva el estudio geológico del entorno de la cueva de Praileaitz I ha abordado la descriptiva geológica del entorno de la cavidad, la descriptiva de la propia cueva, su modelado, rellenos endokársticos, datación de los eventos, caracterización preliminar del agua de goteo e interpretación paleoambiental para cada nivel arqueológico, a partir de las características del sedimento.

\section{2.- LOCALIZACIÓN GEOLÓGICA}

La cueva de Praileaitz I se sitúa al sur de la localidad de Deba, desarrollada en la Formación de las Calizas de Erlo (Fig. 1c; AGIRREZABALA, 1996), calizas micríticas de plataforma somera con rudistas y corales del Aptiense medio. Desde el punto de vista estructural 
el área de estudio se encuadra dentro del Arco Vasco, en el flanco norte del Anticlinorio Nor-Vizcaíno. Se trata de una estructura anticlinal limitada al norte y al sur por sendos accidentes alpinos, con afloramientos urgonianos de edad Aptiense-Albiense en el núcleo. Las calizas albienses del ámbito de la cueva de Praileaitz I forman parte del Monoclinal de Zumaia que aflora a lo largo de toda la franja costera guipuzcoana, presentan una dirección $\mathrm{N} 120^{\circ} \mathrm{E}$ (Fig. 1a) con buzamiento subhorizontal, o ligeramente buzante al norte $\left(20^{\circ}\right)$ (Fig. 1c) y se caracteriza por presentar materiales de edad Cretácico Medio hasta Terciarios buzantes al norte. En las inmediaciones del monte que alberga la cueva de Praileaitz I destaca la existencia de una falla inversa al norte del montículo calizo que queda en frente de Praileaitz I y fallas normales, de menor envergadura de dirección aproximada $\mathrm{N}-\mathrm{S}$.

\section{3.- METODOLOGÍA DE TRABAJO}

El muestreo de sedimento se ha centrado fundamentalmente en las dos primeras salas, del interior de la cavidad, y en la zona de la entrada, aunque se hayan tomado muestras de superficie a lo largo de toda la cueva. El estudio hidrogeológico ha sido realizado en base a cuatro puntos de goteo distribuidos a lo largo de la cavidad (Fig. 2).

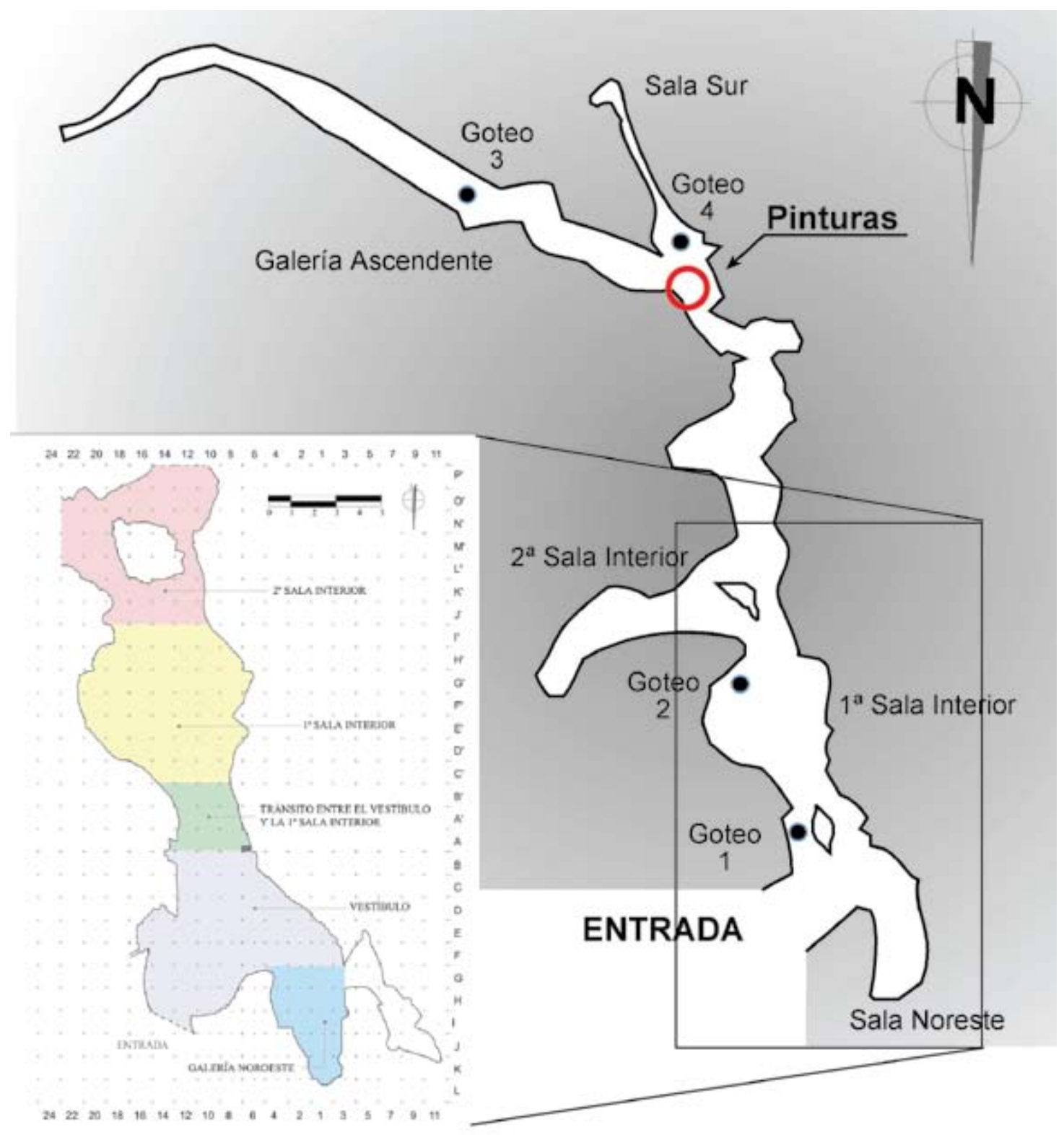

Fig. 2. Planta de la cueva de Praileaitz I y situación del muestreo hidrogeológico (goteo). / Topography of Praileaitz Cave I and location of the hidrogeological samples (dripping). 


\subsection{Análisis granulométricos}

Los análisis granulométricos han sido llevados a cabo en los laboratorios de Sedimentología, de la Sociedad de Ciencias ARANZADI. La metodología empleada es la descrita por LAVILLE (1975) y MISKOWSKY (1974) en sus trabajos efectuados en los yacimientos franceses.

\subsection{Mineralogía de muestra total mediante di- fracción de rayos $x$ (DRX)}

Los análisis mineralógicos de la fracción arcillo-limosa se han realizado en los servicios generales de la Universidad del País Vasco/Euskal Herriko Unibertsitatea (UPV/ EHU), siguiendo un protocolo de actuación estándar.

Una parte alícuota de cada muestra fue molida manualmente en un mortero de ágata y estudiada por difracción de rayos $X(D R X)$, en un difractómetro cuyas características son:

- Difractómetro Philips PW1710 con generador PW1729.

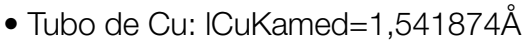

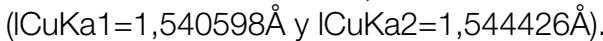

- Corriente del generador: $40 \mathrm{KV}$ y 20 mA.

- Goniómetro vertical PW1050/25 (geometría BraggBrentano).

- Rendija automática de divergencia PW1386/55.

- Intercambiador automático de muestras PW1170.

- Monocromador secundario de grafito.

- Panel de control automatizado conectado a un ordenador IBM PS/2, que controla el difractómetro a través del software específico de la casa Philips APD v.3.

Además, sobre los difractogramas obtenidos se ha realizado una identificación de los minerales presentes y una estimación semicuantitativa, cuyo margen de error relativo es inferior al 10\%. Dicha estimación se basa en la medida de las áreas de ciertas reflexiones características, para cada uno de los minerales presentes, posteriormente corregidas por un factor o poder reflectante (SCHULTZ, 1964):

\begin{tabular}{|c|c|c|}
\hline MINERAL & d((̊) & P.R. \\
\hline Cuarzo & 3,34 & 1,5 \\
\hline Filosilicatos & 4,45 & 0,1 \\
\hline Feldespato K & 3,24 & 1 \\
\hline Hidroxiapatito & 2,81 & 1 \\
\hline
\end{tabular}

No obstante, debe precisarse que para la estimación del contenido en cuarzo se le ha restado a su área el área de la reflexión a $10 \AA$ de la mica, dado que la reflexión $3,34 \AA ̊$ del cuarzo y la $3,31 \AA$ de la mica se superponen y las dos reflexiones de mica consideradas son muy similares. Por otra parte la clorita no se incluiría dentro del contenido en filosilicatos, por no presentar reflexión a $4,45 \AA$. Esta evaluación semicuantitativa da muy buenos resultados al compararse muestras de similar composición bajo la misma rutina.

\subsection{Mineralogía de arcillas de la fracción $<2 \mu \mathrm{m}$ (agregados orientados)}

Los análisis mineralógicos en la fracción fina $(<2 \mu \mathrm{m})$ se han realizado en los servicios generales de la UPV/ EHU, siguiendo un protocolo de actuación estándar.

Se ha preparado una suspensión acuosa a partir de la fracción fina separada de cada muestra, a fin de confeccionar agregados orientados $(\mathrm{AO})$ sobre portas de vidrio por decantación simple. Estos agregados orientados sirven para potenciar las reflexiones (00I) características de cada grupo de los minerales de la arcilla, y así poder identificarlos mediante DRX (MOORE, REYNOLDS, 1997).

El procedimiento seguido ha consistido básicamente en los siguientes pasos:

- Secado de cada muestra en la estufa $\left(24\right.$ h a $\left.40^{\circ} \mathrm{C}\right)$ y posterior pesada de la misma.

- Preparación de una suspensión acuosa de cada muestra, desagregando las partículas mediante baño de ultrasonidos y atrición mecánica.

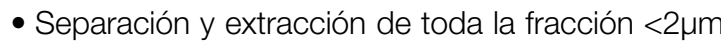
de cada muestra mediante repetidos ciclos de centrifugación (basándose en la Ley de Stokes).

- Concentración de la fracción fina separada mediante floculación con $\mathrm{CaCl} 2$ y centrifugación.

- Secado (24 h a $40^{\circ} \mathrm{C}$ ) y posterior pesada de la fracción fina.

Así, esos agregados orientados han sido estudiados haciendo uso del difractómetro anteriormente citado. Además, se han llevado a cabo una serie de tratamientos específicos para corroborar la identificación de diferentes tipos de minerales de la arcilla: solvatación con etilénglicol (AOEG), solvatación con dimetilsulfóxido (AODM), tratamiento térmico a $550^{\circ} \mathrm{C}(\mathrm{AO550})$, homoionización con Mg y solvatación con glicerina (AOGLI).

De manera similar a lo descrito para la mineralogía de muestra total, para la estimación semicuantitativa del contenido de los distintos tipos de minerales de la arcilla en lafracción $<2 \mu \mathrm{m}$ se han medido las áreas de los picos en AOEG y se han aplicado los siguientes poderes reflectantes:fracción $<2 \mu \mathrm{m}$ se han medido las áreas de los picos en AOEG y se han aplicado los siguientes poderes reflectantes:

\begin{tabular}{|c|c|c|}
\hline MINERAL & d(竎) & P.R. \\
\hline Illita & 10 & 1 \\
\hline Esmectita & 17 & 4 \\
\hline Caolinita & 7,16 & 2 \\
\hline
\end{tabular}

\subsection{Estudio hidrogeológico}

Se han estudiado las características del medio físico en el interior y exterior de la cavidad y se han recopilado datos de los parámetros ambientales de la atmósfera interna y externa (temperatura, humedad relativa y 
concentración de $\mathrm{CO}_{2}$ ), así como de las aguas de goteo, para caracterizar la hidroquímica.

a) Medidas de parámetros ambientales. Los parámetros atmosféricos se han registrado con un medidor de temperatura, humedad relativa y concentración de $\mathrm{CO}_{2}$. Este dispositivo ha permitido realizar medidas puntuales de la atmósfera exterior y en varias salas de la cavidad. Del mismo modo, se ha registrado, con una frecuencia de 30 minutos, la temperatura, humedad relativa y el $\mathrm{CO}_{2}$ durante el periodo comprendido entre el 10 de diciembre y el 17 de diciembre de 2007 en la sala de las pinturas.

b) Medida de parámetros hidrogeoquímicos. Para obtener la información hidrogeoquímica de las aguas se han recogido muestras en cuatro puntos de goteo (Fig. 2) representativos de la cavidad (vestíbulo, primera sala interior, galería ascendente y sala de las pinturas). Se han medido los valores de temperatura del agua, $\mathrm{pH}$, conductividad eléctrica, iones $\left(\mathrm{Li}^{+}, \mathrm{Na}^{+}, \mathrm{K}^{+}, \mathrm{Ca}^{2+}, \mathrm{Mg}^{2+}, \mathrm{HCO} 3, \mathrm{C}\right.$, $\mathrm{NO}_{3}^{-}$y $\mathrm{SO}_{4}{ }^{2-}$ ), así como carbono orgánico disuelto (COD). La analítica se ha realizado en el laboratorio de Hidrogeología de la Universidad de Málaga.

Los valores hidroquímicos derivados de esta campaña deben considerarse representativos sólo del día del muestreo, ya que la dinámica de las cavidades kársticas es muy variable, al influir en ellas, entre otros parámetros, la recarga de lluvia, el almacenamiento del agua en la capa edáfica o los cambios estacionales de la atmósfera exterior.

\section{4.- RESULTADOS}

\subsection{Marco geomorfológico del entorno de Prai- leaitz I}

Aunque la actuación de la cantera haya desfigurado notablemente el relieve inicial del monte de Praileaitz I, mapas topográficos antiguos y los relieves de los montes circundantes revelan la existencia de un modelado kárstico que genera relieves cónicos o incluso hemiesféricos, más o menos aislados, y de cotas similares en torno a $130 \mathrm{~m}$ (Fig. 1). El encinar que cubre las laderas de los montes impide observar, con detalle, la superficie meteorizada de las calizas, pero en el camino que se recorre para acceder a la entrada de la cueva de Praileaitz I se observa un lapiaz parcialmente cubierto.

La entrada de la cueva de Praileaitz I, que no es más que la intersección del sistema kárstico con la ladera, está localizada en la cara NE del monte a una cota aproximada de $55 \mathrm{~m}$ sobre el nivel del mar. La intersección del sistema kárstico se produce a través del río Deba que atraviesa los macizos kársticos de Arno e Izarraitz, encañonándose en los tramos más abruptos y cruzando poljes como el de Astigarribia en los tramos más suaves.
Los relieves de los montes circundantes revelan la existencia de un modelado exokárstico que genera relieves cónicos o incluso hemiesféricos, más o menos aislados, de grandes dolinas de cotas en torno a 130 $\mathrm{m}$, que en el detalle muestran un lapiaz parcialmente cubierto. Este modelado kárstico podría ser definido como "karst poligonal" (WILLIAMS 1971, 1972), "Tower karst" (SWEETING, 1995), o "Cockpit karst" con interdepresiones cónicas, típico de regiones húmedas templadas y tropicales. Esta topografía en caja de huevo, generada por disolución a partir de una superficie posiblemente de carácter erosivo, se extiende desde la costa actual siguiendo el valle fluvial hasta el meandro de Sasieta (inmediaciones de la cueva). Es por ello que, aunque la litología del sustrato sea la misma, los relieves que quedan hacia el interior del valle, presentan cotas mucho más elevadas (en torno a 350- $400 \mathrm{~m}$ de altitud). La gran dolina del entorno de Praileaitz I, con su base a 48-50 m, separa los montes de cotas de $150 \mathrm{~m}$ de las superiores a $350 \mathrm{~m}$ (ARANBURU et al., 2015).

Junto a estos relieves cónicos y grandes dolinas, la incisión del valle fluvial y sus fases de relleno también merecen ser destacados. La correspondencia en cota de Praileaitz I con otras cuevas horizontales y unidades geomorfológicas del macizo kárstico, señalan una superficie de estabilidad freática para el momento de la formación de la cavidad (ARRIOLABENGOA et al., 2012; ARANBURU et al., 2015; ARRIOLABENGOA, 2015).

\subsection{Rasgos karsticos de la cueva de Praileaitz I}

Los sistemas kársticos no son sistemas estables que, una vez desarrollados, se desactivan, sino que continúan evolucionando siguiendo las variaciones del nivel base del agua. De esta manera, a medida que el valle fluvial exterior se va encajando y desciende en cota, las distintas zonas del karst evolucionan (inciden) junto con él. El modelo kárstico que observamos hoy en día en la zona de Sasieta no es, por tanto, más que la suma total de los procesos acaecidos desde que el agua empezó a formar el valle abriéndose camino a través de las rocas carbonatadas hasta hoy en día (ARANBURU et al. , 2015).

Estructuralmente, la cavidad se encuentra atravesada por 3 familias de discontinuidades que controlan, entre otras características, el desarrollo de espeleotemas y galerías internas (IRIARTE et al., 2010).

A tenor de lo observado en la parte accesible y conocida de la cueva, Praileaitz I presenta un desarrollo subhorizontal muy marcado de reducidas dimensiones: en torno a $100 \mathrm{~m}$ de longitud, $3 \mathrm{~m}$ de ancho y una sección subcircular (algo ovalada hacia su extremo SE). A lo largo del conducto se observan distintos rasgos fluviokársticos, como por ejemplo (Fig. 3):

- Las bóvedas, o techos de conductos subcirculares de la cueva de Praileaitz han sido generadas por corrientes de agua que circulan en la zona freática (galería subhorizontal) y poco remodeladas en condiciones vadosas. Completando la sección, en base 

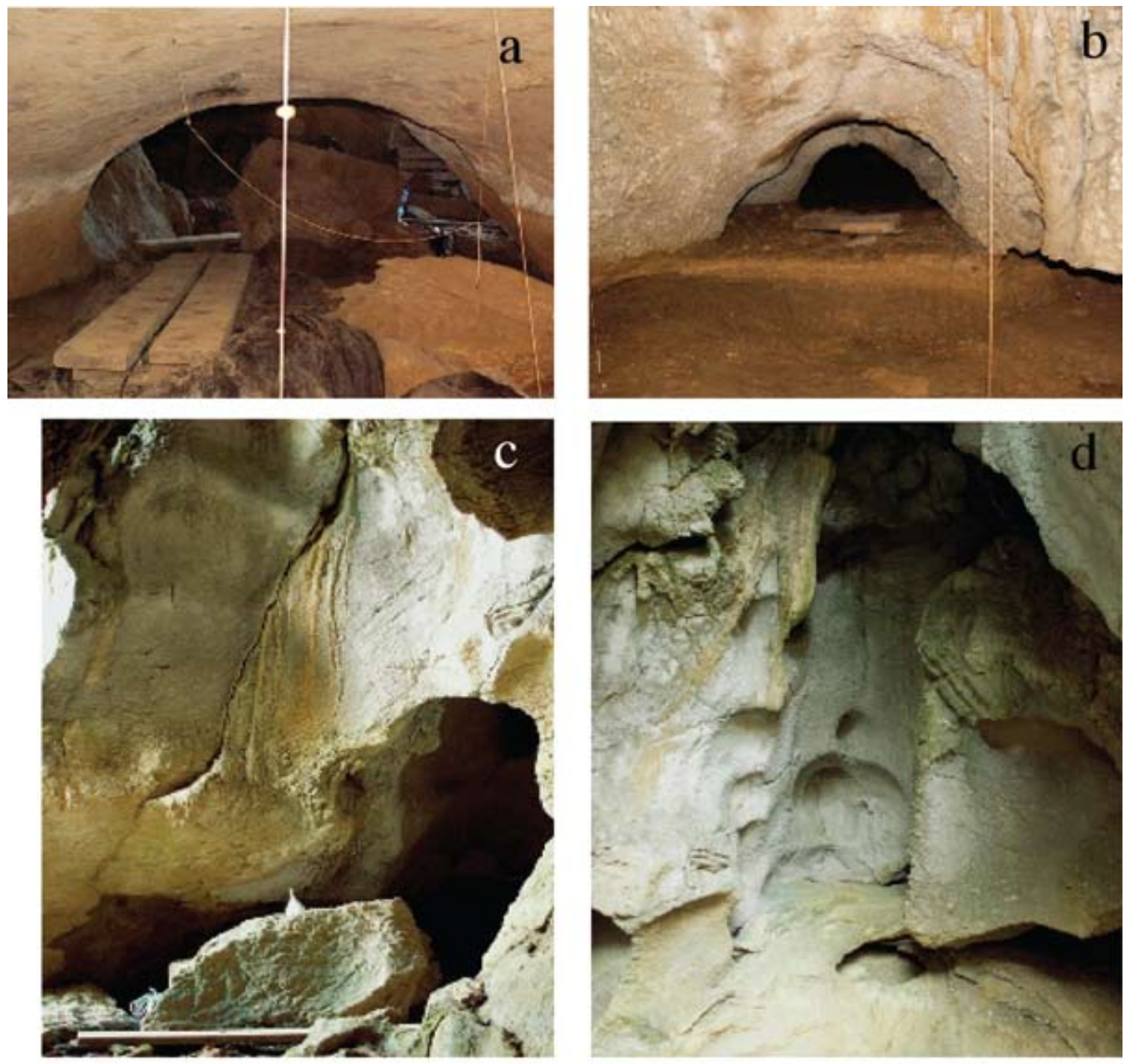

e
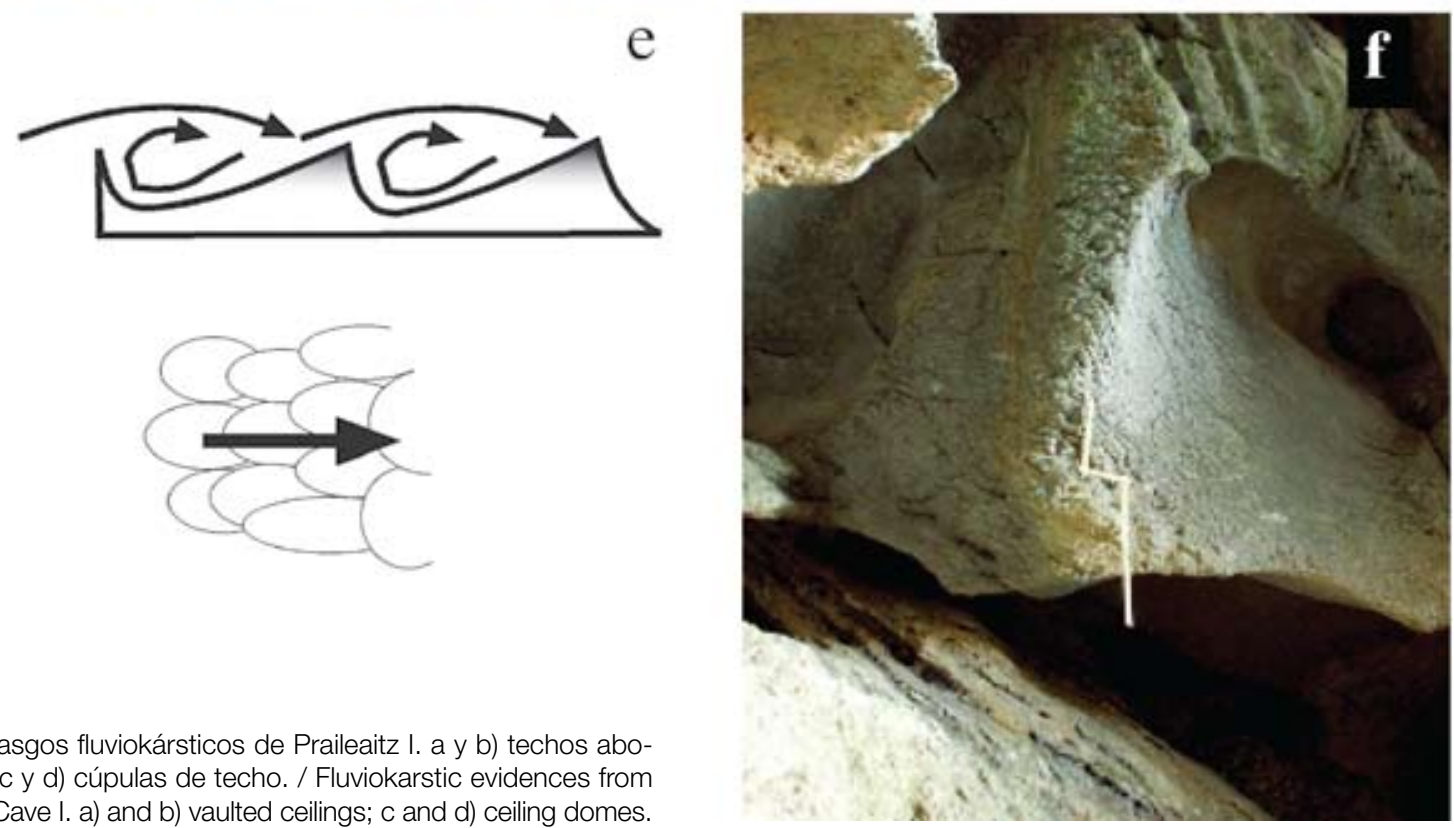

Fig. 3. Rasgos fluviokársticos de Praileaitz I. a y b) techos abovedados; c y d) cúpulas de techo. / Fluviokarstic evidences from Praileaitz Cave I. a) and b) vaulted ceilings; $c$ and d) ceiling domes. 
al arco de bóveda que queda sin cubrir por el sedimento, se infiere que el conducto freático podría tener un desarrollo vertical de 2,5-3 m (Fig. 3, a y b).

- Las marcas de agua generadas por erosión (golpes de gubia o scalops) se identifican a lo largo de toda la galería indicando una dirección de paleoflujo desde SSE y E (segunda sala interior) en sentido N (Fig. 3, c y d).

- Sima vertical de 12 m, localizada en la entrada. Las marcas de agua, de escala decimétrica, indican un paleoflujo ascendente, evidenciando la existencia de una surgencia en tiempos activos del karst, en lo que hoy en día es la entrada.

- Estructuras de disolución, formadas por el ataque químico del agua más o menos estancada. El mejor ejemplo lo conforman las pequeñas bolsadas o cúpulas de techo (ceiling pockets) formadas por disolución preferencial (sala noreste y en el tránsito entre primera y segunda sala interior, por ejemplo, Fig. 3e).

Todos estos rasgos fluviokársticos apuntan hacia un modelo de galería de tipo nivel freático o de agua. Es muy

\section{SEDIMENTO DETRÍTICO}

\section{Autóctono: Meteorización de la roca} Fracturación mecánica de la roca Fracción insoluble de la roca

\section{Alóctono}

- Gravitacional: Depósitos de talud (exterior)

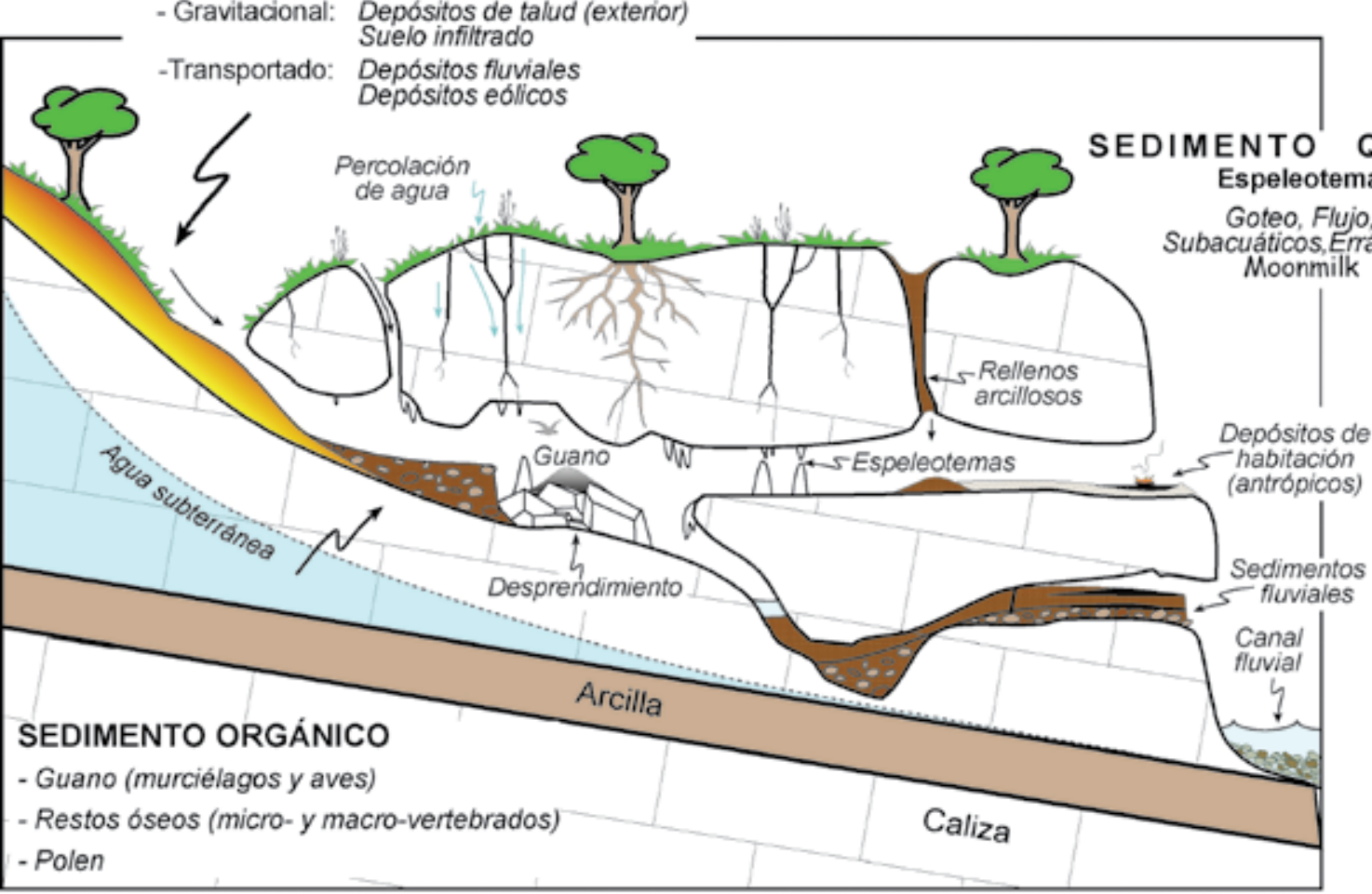

modificado de Gillieson (1996) frecuente en zonas con estratificación subhorizontal, donde el asentamiento del conducto viene marcado por a) el contacto con rocas más impermeables o b) por el nivel de base del río, donde se desarrollan conductos subhorizontales de secciones más o menos subcirculares.

La existencia de conductos verticales con marcas de flujo ascendentes como el de la entrada encaja, sin embargo, con modelos de tipo freático profundo. Son aquellos conductos generados en la zona saturada de agua y donde el movimiento del agua, lento en general, puede producirse tanto en la vertical (ascendente o descendente) como en la horizontal.

La coexistencia de ambos tipos de modelado no es más que el fruto de la evolución del karst, pasando de condiciones freáticas profundas a condiciones de nivel de agua, según el nivel freático ha ido descendiendo por el encajamiento del nivel de base marcado por el río hasta las condiciones vadosas en el que tuvo lugar la sedimentación, y ocupación de la cueva hasta la actualidad.

\subsection{Estratigrafía endokárstica}

\subsubsection{Sedimentos detríticos de la cueva Praileaitz I}

Los depósitos detríticos de cuevas están formados por partículas que proceden de la erosión, transporte y 


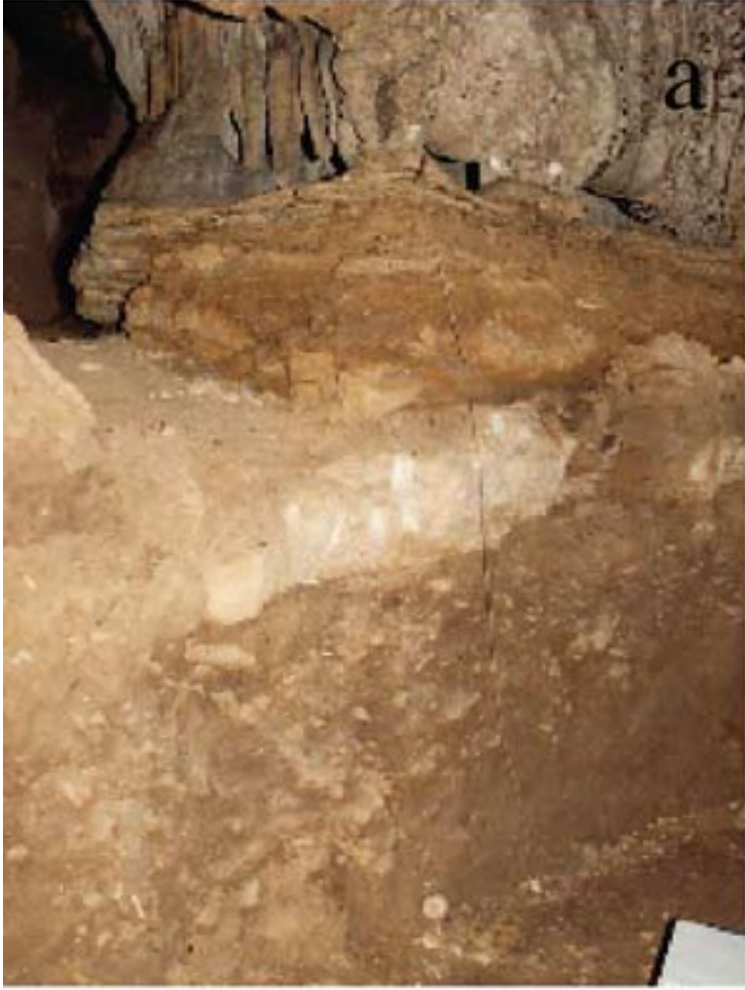

Fig. 5. Secciones y catas donde se observa la estratigrafía del relleno: a) Sala norte; b y c) segunda sala interior. / Sections and sampled points where cave filling stratigraphy have been observed: a) north room; $b$ and c) second inner room.

sedimentación de otras rocas o depósitos preexistentes, o del desmantelamiento de suelos. En depósitos de cuevas, éstos pueden proceder del exterior de la cueva y ser transportados hasta el sistema kárstico (alóctonos) o bien ser producto de la alteración tanto física como química de la propia roca que alberga el sistema kárstico (autóctonos) (Fig. 4). Así podemos encontrar desde fragmentos de roca caídos de las paredes o el techo (fracturación) hasta los residuos insolubles de la caliza sometida a disolución.

Antes de pasar a describir los tipos de sedimentos alóctonos que predominan en la cueva de Praileaitz I, es necesario subrayar que las observaciones están limitadas a las superficies y secciones de excavación. La máxima potencia estratigráfica observada es de 1,6 m en la sala Norte y $50 \mathrm{~cm}$ en la cata de la primera sala interior (Fig. 5).

Cabe destacar que todos los sedimentos observados en la cueva de Praileaitz I corresponden a la fase de relleno vadoso de la misma, y no a la fase freática activa de la cueva. Han sido distinguidos los siguientes tipos de sedimentos detríticos:

1.- Sedimentos detríticos autóctonos: generados por fracturación mecánica de las paredes de la roca caliza, producen fragmentos angulosos que pueden tener dimensiones desde decimétricas (bloques) hasta centimé-
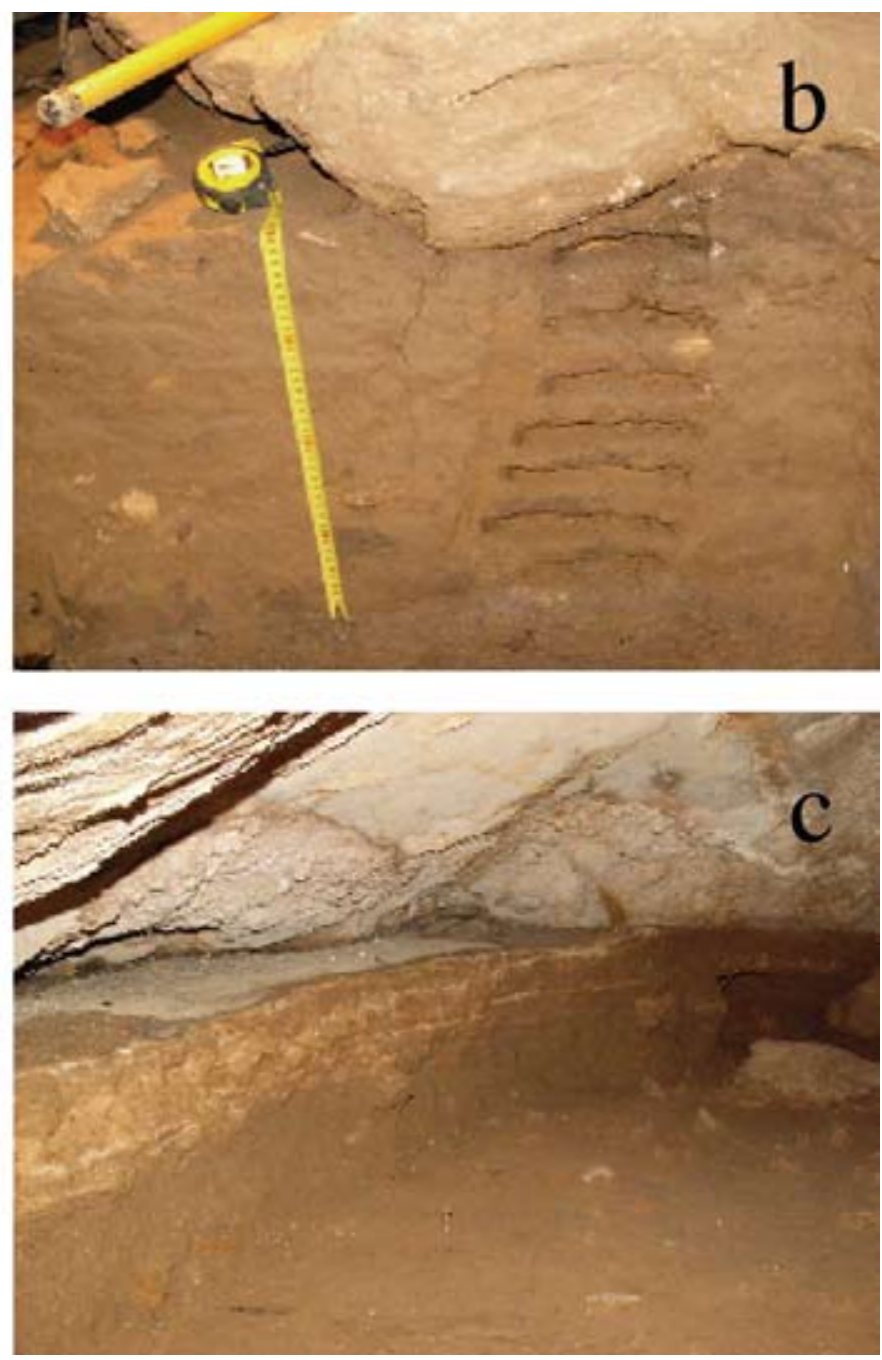

tricas (éboulis). Al final de la galería ascendente (SE) hay bloques de colapso (gravedad) apilados de forma desordenada dando una acumulación altamente permeable. Y en la sala norte, $60 \mathrm{~cm}$ por debajo de la superficie encostrada, los bloques calizos aparecen englobados por la matriz de niveles estratigráficos superiores (Fig. 6). Los éboulis, sin embargo, relacionados con la fragmentación de la roca por variaciones de temperatura (crioclastia; LAVILLE et al., 1980), solamente han sido observados en los sedimentos de la sala norte y la entrada, mezclados con la sedimentación alóctona y/o antrópica. La mayoría son fragmentos calizos o de espeleotemas angulosos planares, de 2,5 a $4 \mathrm{~cm}$ de diámetro máximo o entre 7 y $10 \mathrm{~cm}$ (Fig. 6).

2.- Sedimentos detríticos alóctonos. Las partículas procedentes del exterior del sistema kárstico pueden llegar a él bien por acción gravitacional y/o transportadas por el agua. Dentro de los sedimentos gravitacionales podemos diferenciar los depósitos de talud, normalmente en las bocas de las cuevas, y el suelo exterior infiltrado rellenando distintos tipos de conductos. En la boca de la 
Fig. 6. Sedimentos detríticos autóctonos: a) Bloques calizos de la roca encajante (sala norte); b) éboulis en el relleno sedimentario (sala norte); c) alteración de la roca que puede desencadenar en la formación de fragmentos calizos tipo éboulis. / Autochthonous detrital sediments: a) limestone host rock blocks (north room); b) éboulis in the sedimentary infill (north room); c) alteration of the host rock (cretaceous limestone) that can trigger the formation of éboulis type fragments.
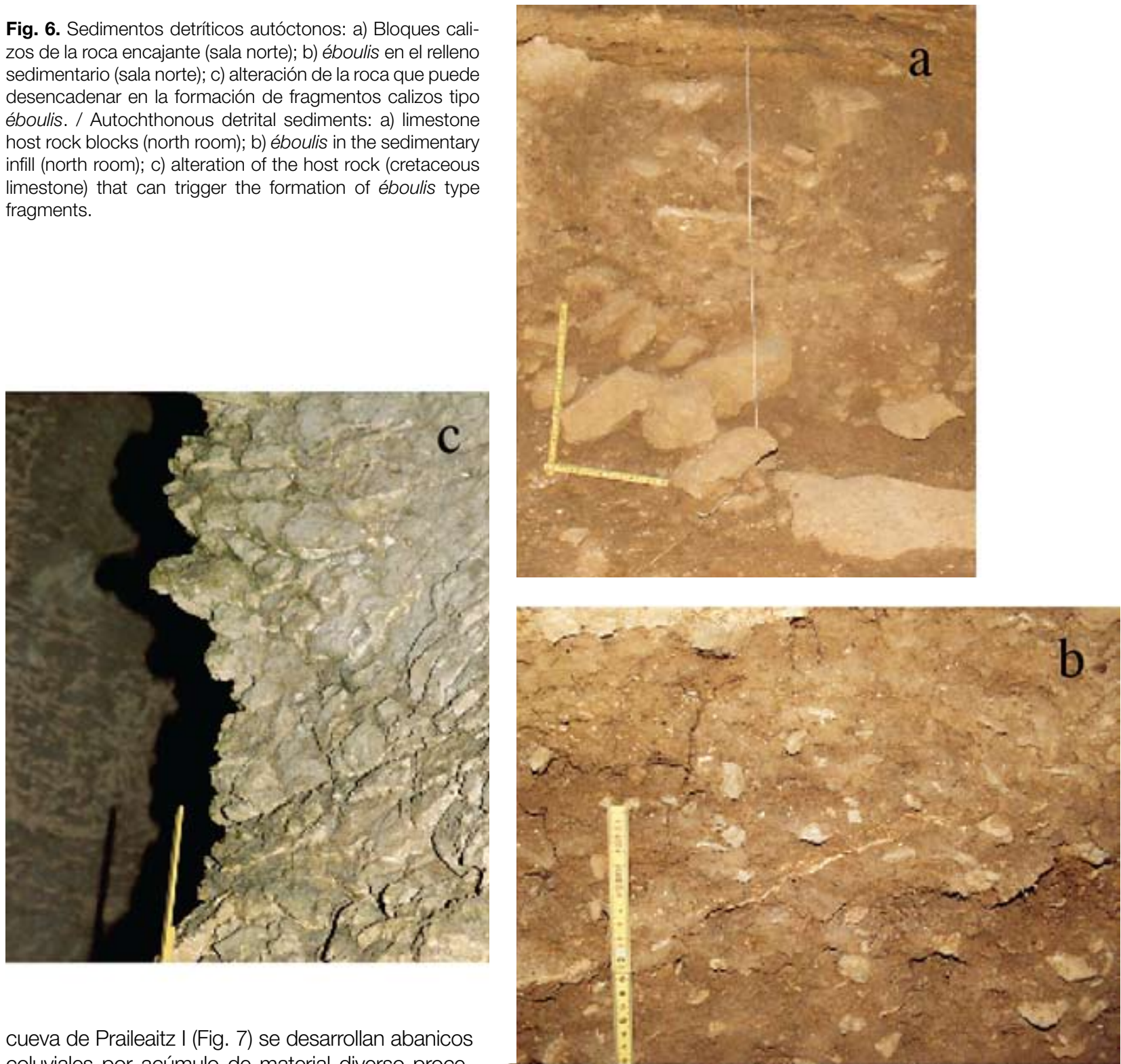

cueva de Praileaitz I (Fig. 7) se desarrollan abanicos coluviales por acúmulo de material diverso procedente de la meteorización superficial de la roca: bloques de roca, suelo, restos vegetales/animales, etc. Es un depósito no seleccionado, no consolidado, con partículas angulosas poco o nada retrabajadas y pobremente estratificado. Parte importante de los sedimentos de la entrada de la cueva han sido excavados en campañas anteriores, pero los testigos que quedan adheridos a las paredes, la estratigrafía que se observa en la sala norte, así como la inclinación de los distintos niveles sedimentarios, refuerzan esta hipótesis.

Los sedimentos detríticos tractivos, transportados por el agua, conforman el segundo tipo de sedimento y afloran a lo largo de la galería principal. Desde la entrada actual de la cueva y hasta la sala sur (conducto de dirección NW-SE) (Fig. 7), pasando por la sala de las pinturas, por debajo de la costra carbonatada que sella la sedimentación de la cueva, los sedimentos detríticos

son bimodales con predominio de matriz limo-arcillosa y abundantes nódulos de limonita, cantos redondeados de cuarcita blanca y areniscas. La limonita (FeO $\cdot \mathrm{OH} \cdot \mathrm{nH} 2 \mathrm{O})$, que se genera como resultado de la mezcla de diversos hidróxidos de hierro (goethita y lepidocrocita) con arcilla, puede proceder de la oxidación de la pirita, mineral frecuente en las calizas urgonianas del entorno o formaciones siliciclásticas circundantes. El hierro férrico es casi inmóvil en ambientes oxidantes neutrales pero no así en aguas ácidas, pudiéndose concentrar, en forma de nódulos o pepitas en los suelos. Los cantos de cuarcita blanca y arenisca, sin embargo, no proceden de la alteración de la roca carbonatada.

Estas partículas, proceden de las unidades litoestratigráficas siliciclásticas del Albiense medio, parte alta o superior (como, por ejemplo, la Formación Conglome- 


\section{SEDIMENTOS DETRÍTICOS ALÓCTONOS}

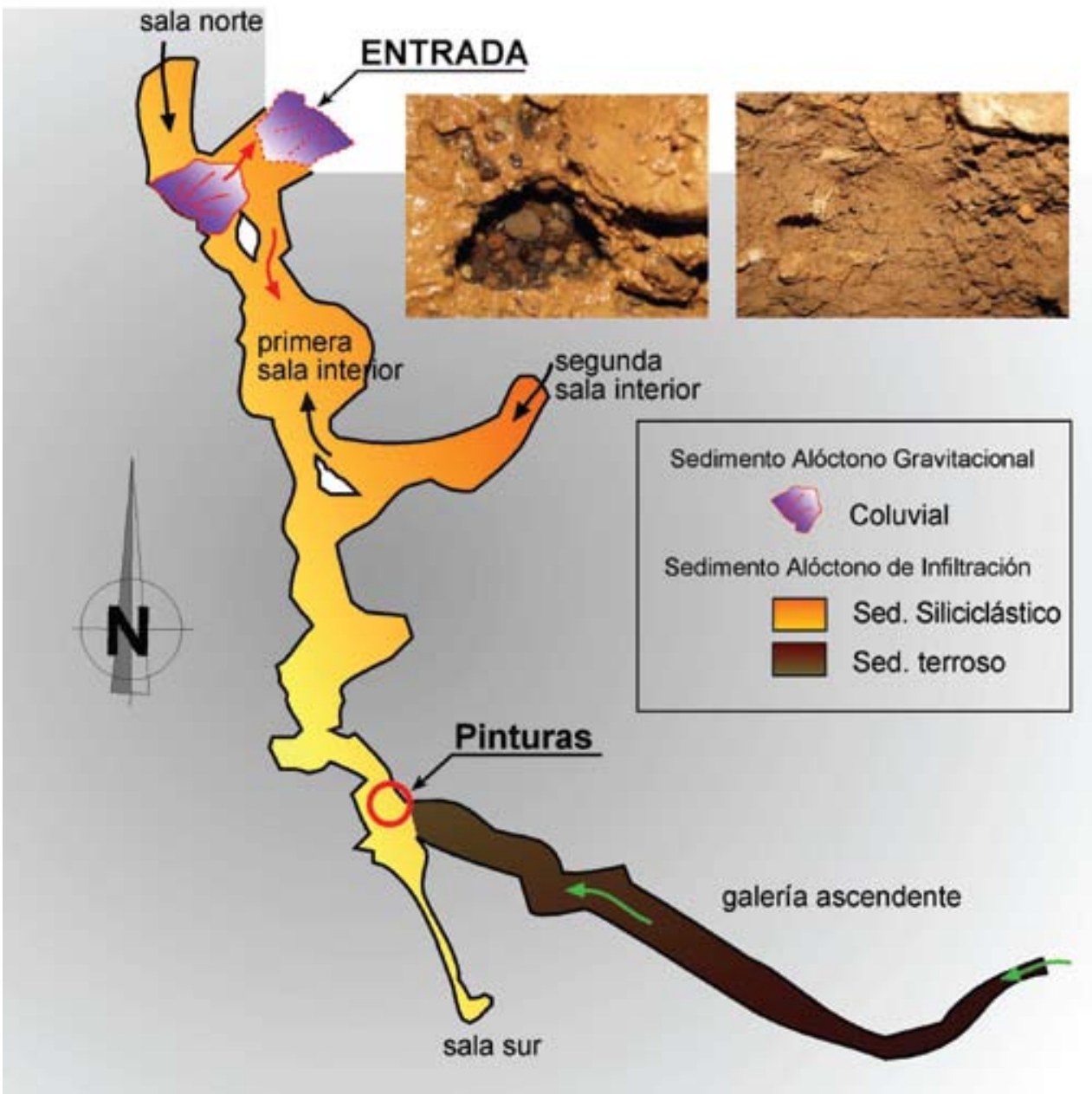

Fig. 7. Mapa de distribución de sedimentos detríticos alóctonos a lo largo de la Cueva de Praileaitz I. / Distribution map of different allochthonous detrital sediments along the Praileaitz Cave I.

rados de Ondarroa; AGIRREZABALA, 1996). Los componentes siliciclásticos han podido ser transportados por el agua desde unidades siliciclásticas circundantes (karst alogénico). El desarrollo de conductos únicos está determinado por el predominio de la recarga alogénica, mientras que el desarrollo de conductos muy ramificados puede indicar un mayor predominio de recarga autigénica y circulación interna. Sería necesaria la realización de un estudio más regional, abarcando a todo el sistema kárstico o todas las cuevas conocidas del lugar para discernir entre estas dos hipótesis de partida.

Independientemente de la procedencia de las partículas detríticas siliciclásticas, la entrada de las mismas a la cueva tuvo lugar desde distintos puntos, a priori, de la ladera NNE (sala norte, segunda sala interior y sala sur).

Los sedimentos detríticos infiltrados, transportados más o menos en la vertical por la acción de la gravedad y el agua, conforman el segundo tipo de sedimento y afloran a lo largo de la galería principal. El área fuente de estos depósitos se localiza en los suelos lavados y/o deslizados, y no necesariamente generados en el propio macizo calizo. A diferencia de los depósitos de boca de cueva, éstos pueden padecer cierta criba al infiltrarse por pequeñas grietas, simas o dolinas, habiendo un sesgo hacia granulometrías finas (arenas y arcillas). En la galería ascendente (Fig. 7), sin embargo, el sedimento infiltrado descansa por encima de una costra carbonatada (quizás la misma que sella la sedimentación previamente descrita), no se han observado cantos detríticos y no se encuentran nódulos de limonita (sedimento unimodal). La matriz, de granulometría limo-arcillosa, engloba abundantes fragmentos de carbón, restos óseos y caracoles no fosilizados. Cabe destacar la presencia de hojas al final de la galería ascendente, atrapados en las fisuras entre bloques.

A falta de estudios más detallados, la interpretación de este sedimento corresponde a la infiltración del suelo situado en la vertical (calizas), a través de la zona de colapso, situado en el extremo E de la galería ascendente. La abundancia de fragmentos carbonosos podría re- 
lacionarse con un incendio, desmantelamiento del suelo vegetal y reactivación de las fisuras como vías de entrada de sedimento a la cueva.

\subsubsection{Análisis granulométrico de los niveles ar- queológicos}

El objetivo de este apartado es el análisis e interpretación de cada nivel arqueológico, a partir de las características del sedimento. Para ello, se han recogido muestras en diferentes zonas del yacimiento (Fig. 2):

a) Columna $A$ que contiene las muestras $A 1$ a A24, se recogen en el $6 \mathrm{~A}$ de la cuadrícula de excavación. Toda esta columna es muy homogénea; la sedimentación ha sido mayor que en otras zonas de la cavidad y es difícil diferenciar los distintos niveles.

b) Columna $B$, se recoge en el límite de los cuadros 3F/3G y las muestras se rotulan como B1 a B15. En esta columna se distinguen dos niveles de acumulación de materiales gruesos, entre los que se intercalan niveles de material fino. Todo el sedimento se encuentra sellado por una capa de concreción.

c) Un tercer grupo de muestras, Muestreo C, rotuladas $\mathrm{C} 1$ a $\mathrm{C} 11$, se recogieron en diferentes zonas de la cavidad: cuadros 8C', 8B', 18E', 8F' y 10J', en la primera sala interior, en el final del pasillo que da acceso a dicha sala y, por último, en el arranque a la segunda sala interior y no constituyen una verdadera columna sedimentológica.

\subsubsection{Columna A}

En las tablas 1 y 2 se presentan los resultados del análisis del laboratorio para la granulometría global (Tabl. 1) y para la granulometría de arenas e índices estadísticos (Tabl. 2).

\begin{tabular}{|c|c|c|c|c|c|c|c|c|c|c|c|}
\hline & & $\mathbf{Z}$ & cantos & Gran grs & Gran fn & $\begin{array}{c}\% \\
>2 \mathrm{~mm}\end{array}$ & $\begin{array}{c}\% \\
<2 \mathrm{~mm}\end{array}$ & $\%$ arenas & $\%$ limos & $\%$ arcillas & $\begin{array}{c}\text { Q50 } \\
<2 \mathrm{~mm}\end{array}$ \\
\hline \multirow{4}{*}{ U-1.1 } & $\mathrm{A} 1$ & 195 & 0,3 & 0,42 & 2,33 & 3 & 97 & 27 & 41 & 32 & 0,015 \\
\hline & $\mathrm{A} 2$ & & 0,6 & 0,2 & 1,65 & 2 & 98 & 34 & 38 & 28 & 0,022 \\
\hline & A3 & & 0 & 0,29 & 1,36 & 2 & 98 & 32 & 34 & 34 & 0,024 \\
\hline & A4 & 215 & 0 & 0,16 & 0,63 & 1 & 99 & 32 & 38 & 30 & 0,02 \\
\hline \multirow{7}{*}{ U-1.2 } & A5 & 224 & 0 & 0 & 0,38 & 0 & 100 & 29 & 34 & 37 & 0,018 \\
\hline & A6 & & 0 & 0,47 & 0,99 & 1 & 99 & 29 & 39 & 32 & 0,018 \\
\hline & A7 & & 0,4 & 0,21 & 1,1 & 2 & 98 & 34 & 30 & 36 & 0,022 \\
\hline & A8 & & 0 & 0,79 & 1,14 & 2 & 98 & 34 & 32 & 34 & 0,013 \\
\hline & A9 & & 1,2 & 0,11 & 1,99 & 3 & 97 & 31 & 27 & 42 & 0,013 \\
\hline & A10 & & 1 & 0,2 & 2,45 & 4 & 96 & 39 & 33 & 28 & 0,025 \\
\hline & A11 & 269 & 0 & 0,11 & 1,4 & 1 & 99 & 36 & 26 & 38 & 0,02 \\
\hline \multirow{3}{*}{ U-1.3 } & A12 & 275 & 0 & 0,36 & 2,11 & 2 & 98 & 36 & 41 & 23 & 0,022 \\
\hline & A13 & & 0 & 0,37 & 2,47 & 3 & 97 & 43 & 31 & 26 & 0,038 \\
\hline & A14 & 289 & 0 & 0,12 & 2,72 & 3 & 97 & 34 & 39 & 27 & 0,026 \\
\hline \multirow{4}{*}{ U-1.4 } & A15 & 291 & 3,2 & 1,45 & 5,07 & 9 & 91 & 31 & 39 & 30 & 0,015 \\
\hline & A16 & & 3,7 & 2,11 & 3,86 & 10 & 90 & 35 & 38 & 27 & 0,016 \\
\hline & A17 & & 27 & 8,97 & 8,28 & 45 & 55 & 50 & 26 & 24 & 0,05 \\
\hline & A18 & 301 & 3,8 & 3,33 & 5,86 & 13 & 87 & 37 & 26 & 37 & 0,018 \\
\hline \multirow{6}{*}{ U-1.5 } & A19 & 305 & 0,7 & 0,57 & 1,89 & 3 & 97 & 25 & 33 & 42 & 0,0042 \\
\hline & A20 & & 1,1 & 0,74 & 2,93 & 5 & 95 & 26 & 35 & 39 & 0,009 \\
\hline & A21 & & 12 & 0,6 & 2,9 & 16 & 85 & 27 & 29 & 44 & 0,0046 \\
\hline & A22 & & 13 & 1,05 & 2,6 & 17 & 83 & 29 & 27 & 44 & 0,0046 \\
\hline & A23 & & 0,6 & 1,5 & 3,8 & 6 & 94 & 29 & 24 & 47 & 0,0046 \\
\hline & A24 & 327 & 0,6 & 0,3 & 0,7 & 2 & 98 & 21 & 29 & 50 & 0,002 \\
\hline
\end{tabular}

Tabl. 1. Granulometría global Columna A. / Granulometry of the Column A. 


\begin{tabular}{|c|c|c|c|c|c|c|c|c|c|c|c|c|c|}
\hline & & & & & \multicolumn{3}{|c|}{ Arena } & \multicolumn{2}{|c|}{$\mathrm{mm}$} & \multicolumn{4}{|c|}{ Folk y Word } \\
\hline & & Z & $\begin{array}{l}\% \\
\text { fino }\end{array}$ & arena & \%grues & $\%$ med & \%fin & So & Q50 & $\mathrm{Mz}$ & $\mathrm{Si}$ & Sk1 & K \\
\hline \multirow{4}{*}{$\begin{array}{c}U- \\
1.1\end{array}$} & $\mathrm{~A} 1$ & 195 & 97 & 27 & 30 & 20 & 50 & 2,62 & 0,20 & 2,09 & 1,63 & $-0,21$ & 0,70 \\
\hline & A2 & & 97 & 34 & 18 & 26 & 56 & 2,15 & 0,16 & 2,44 & 1,43 & $-0,26$ & 0,83 \\
\hline & A3 & & 98 & 32 & 15 & 21 & 63 & 2,00 & 0,15 & 2,56 & 1,38 & $-0,27$ & 0,92 \\
\hline & A4 & 215 & 99 & 32 & 15 & 16 & 69 & 1,90 & 0,12 & 2,71 & 1,42 & $-0,44$ & 1,04 \\
\hline \multirow{7}{*}{$\begin{array}{c}\text { U- } \\
1.2\end{array}$} & A5 & 224 & 100 & 29 & 6 & 15 & 79 & 1,60 & 0,10 & 3,11 & 1,05 & $-0,36$ & 1,11 \\
\hline & A6 & & 98 & 29 & 9 & 16 & 74 & 1,71 & 0,11 & 2,94 & 1,17 & $-0,34$ & 1,08 \\
\hline & A7 & & 98 & 34 & 11 & 20 & 70 & 1,80 & 0,12 & 2,81 & 1,25 & $-0,37$ & 0,97 \\
\hline & A8 & & 98 & 34 & 16 & 19 & 65 & 1,91 & 0,14 & 2,54 & 1,39 & $-0,33$ & 1 \\
\hline & A9 & & 97 & 31 & 19 & 21 & 60 & 1,99 & 0,16 & 2,39 & 1,47 & $-0,30$ & 0,96 \\
\hline & $\mathrm{A} 10$ & & 96 & 39 & 17 & 22 & 61 & 1,99 & 0,15 & 2,51 & 1,40 & $-0,30$ & 0,93 \\
\hline & A11 & 269 & 99 & 36 & 24 & 26 & 50 & 2,24 & 0,20 & 2,15 & 1,56 & $-0,19$ & 0,83 \\
\hline \multirow{3}{*}{$\begin{array}{c}\text { U- } \\
1.3\end{array}$} & $\mathrm{~A} 12$ & 275 & 98 & 36 & 21 & 22 & 56 & 2,16 & 0,17 & 2,32 & 1,48 & $-0,25$ & 0,82 \\
\hline & $\mathrm{A} 13$ & & 97 & 43 & 24 & 24 & 52 & 2,21 & 0,19 & 2,17 & 1,53 & $-0,23$ & 0,82 \\
\hline & A14 & 289 & 97 & 34 & 25 & 24 & 51 & 2,26 & 0,20 & 2,13 & 1,55 & $-0,19$ & 0,80 \\
\hline \multirow{4}{*}{$\begin{array}{c}\text { U- } \\
1.4\end{array}$} & A15 & 291 & 90 & 31 & 23 & 23 & 54 & 2,26 & 0,18 & 2,32 & 1,40 & $-0,17$ & 0,72 \\
\hline & $\mathrm{A} 16$ & & 90 & 35 & 33 & 22 & 45 & 2,47 & 0,25 & 1,91 & 1,61 & $-0,09$ & 0,75 \\
\hline & A17 & & 55 & 50 & 40 & 26 & 34 & 2,38 & 0,36 & 1,51 & 1,56 & 0,04 & 0,77 \\
\hline & $\mathrm{A} 18$ & 301 & 87 & 37 & 21 & 24 & 56 & 2,26 & 0,17 & 2,33 & 1,54 & $-0,25$ & 0,82 \\
\hline \multirow{6}{*}{$\begin{array}{c}\text { U- } \\
1.5\end{array}$} & A19 & 305 & 97 & 25 & 20 & 25 & 55 & 2,06 & 0,18 & 2,31 & 1,42 & $-0,21$ & 0,88 \\
\hline & A20 & & 95 & 26 & 25 & 23 & 51 & 2,24 & 0,20 & 2,10 & 1,54 & $-0,22$ & 0,83 \\
\hline & A21 & & 85 & 27 & 31 & 26 & 43 & 2,27 & 0,24 & 1,85 & 1,58 & $-0,17$ & 0,82 \\
\hline & A22 & & 83 & 29 & 32 & 26 & 42 & 2,30 & 0,25 & 1,82 & 1,59 & $-0,14$ & 0,81 \\
\hline & A23 & & 94 & 29 & 30 & 31 & 38 & 2,13 & 0,28 & 1,78 & 1,52 & $-0,06$ & 0,87 \\
\hline & A24 & 327 & 98 & 21 & 18 & 23 & 59 & 2,00 & 0,16 & 2,40 & 1,38 & $-0,28$ & 0,90 \\
\hline
\end{tabular}

Tabl. 2. Granulometría de arenas e índices estadísticos. Columna A. / Sand sized sediment distribution and statistical analysis. Column A.

\section{Análisis e interpretación de los resultados}

\section{Unidad 1.1 a Unidad 1.3: Muestras A1 ( $Z=195)$ a A14 ( $Z=289)$.}

Fracción gruesa.- La fracción gruesa es escasa en toda esta unidad y está representada, sobre todo, por el calibre gránulo fino con materiales muy variados, predominando las concreciones, nódulos ferruginosos, cuarcitas y lutitas rodadas siendo muy escasas las calizas. Dentro de la escasez de materiales superiores a $2 \mathrm{~mm}$, más de la mitad de esa fracción gruesa son materiales no carbonatados y parecen transportados desde el exterior a través de las grietas del lenar. La proporción gránulos gruesos/finos se decanta hacia los más finos en toda la columna (Tabl. 1).

Fracción fina.- La matriz presenta un color marrón amarillento oscuro: 10 YR 4/3 en la escala Munsell. Es muy abundante con un predominio de arenas finas y limos, entrando en la categoría de franco-arcillosa. Las curvas de granulometría tienen forma de $S$ muy tendida que se levanta en estos calibres (Fig. 8).

El valor de la mediana, Q50, oscila entre 0,10 y 0,20 $\mathrm{mm}$. El valor de la media para estas muestras se sitúa en valores de arenas finas. La clasificación es mala, con valores de desviación entre $\mathrm{Si}=1,38$ a 1,63 $\varphi$ lo que significa una mezcla de arenas de diferentes calibres (Fig. 9), dando valores negativos de asimetría, Sk1, con un predominio de arenas finas y una cola de materiales más gruesos.

No hay indicadores de frío. El sedimento se deposita en un clima templado y húmedo, con energía suficiente para transportar algunos pequeños gránulos de lutitas y nódulos ferruginosos aportados por el lenar; aunque predominan los materiales depositados por decantación: arenas finas, limos y arcillas, que componen una matriz franco arcillosa. 

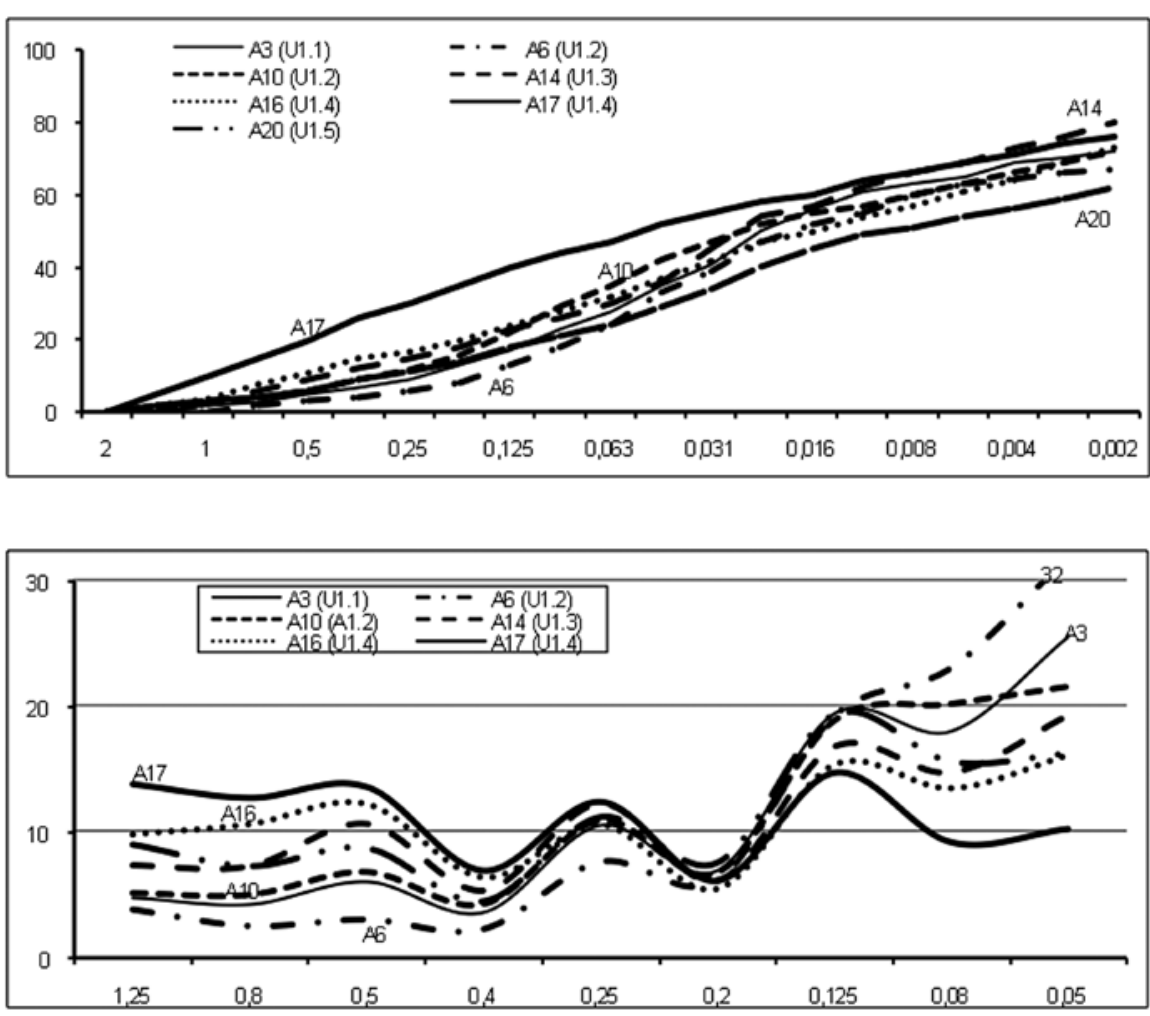

Fig. 8. Curvas de granulometría fracción fina representativas de la Unidad 1. / Fine fraction distribution curves for Unit 1.

Fig. 9. Curvas de la fracción arena representativas de la Unidad 1. / Sand fraction distribution curve for Unit 1.

\section{Unidad 1.4: Muestras A15 $(Z=291)$ a $A 18(Z=301)$.}

Fracción gruesa.- Esta Unidad se caracteriza por el aumento de fracción gruesa sobre todo en la muestra A17. Está constituida esencialmente por fragmentos de concreción tanto en el calibre canto como gránulo. Hay también pequeños cantos calizos, la mayoría con aristas muy desgastadas, y un índice de alteración, $I A=90$. En los gránulos abunda la concreción pero se ven también otros materiales: calizos, algunas lutitas planares y bastantes nódulos ferruginosos sobre todo entre los gránulos más finos.

Fracción fina.- La matriz tiene un color marrón oscuro 10 YR 4/3. Todas las muestras se clasifican como franco arcillosas a excepción de A17 que, con un mayor contenido en arenas, entra en la categoría de franco arcilloarenosa. Los parámetros de la fracción arena siguen presentando valores similares a los del resto de la Columna A. Únicamente las muestras con un mayor contenido en arenas gruesas (A16 y A17) se separan algo de esta tendencia. A18 con asimetría más negativa $(\mathrm{Sk} 1=-0,25)$ representa una aproximación a la unidad infrayacente.

Unidad 1.5: Muestras A19 ( $Z=305)$ a A24 ( $Z=327)$.

Fracción gruesa.- La fracción gruesa es escasa y, cuando aparece, muestras A21 y A22, son fragmentos aislados de concreción caídos de las paredes. En las muestras A19 y A22, aparecen pequeños nódulos ferruginosos. Los mismos materiales se encuentran en los gránu- los, además de lutitas, areniscas y cuarcitas. En general hay predominio de gránulos finos frente a los gruesos. En la morfoscopía de gránulos finos y arenas gruesas, aparecen cristales silíceos muy rodados e incluso minerales de tipo basáltico también muy rodados.

Fracción fina.- La matriz de color marrón amarillento oscuro, 10YR4/4, se puede clasificar como arcillosa (40 a 50\%), encontrándose limos y arenas repartidos en porcentajes semejantes. El alto contenido en arcilla hace que la mediana de la fracción se sitúe en el tamaño limo fino, con valores próximos a 0,005. En las arenas también predominan las arenas finas con valores cercanos al $50 \%$. La clasificación sigue siendo mala y con asimetría negativa. Nos encontraríamos en un momento muy húmedo, con episodios menos húmedos y templado, alternando con momentos más rigurosos.

Cuando se intenta relacionar los parámetros estadísticos para las arenas obtenidos en las diferentes muestras, vemos que todas ellas se agrupan en una nube de puntos que no ofrece diferencias entre las unidades. Sólo las muestras A5, A6 y A7 y la muestra A17 se separan algo del comportamiento general (Fig. 10).

\section{Conclusiones de la Columna A.}

Este primer muestreo realizado en el yacimiento es muy homogéneo y sólo dos momentos han dado alguna diferencia apreciable. 


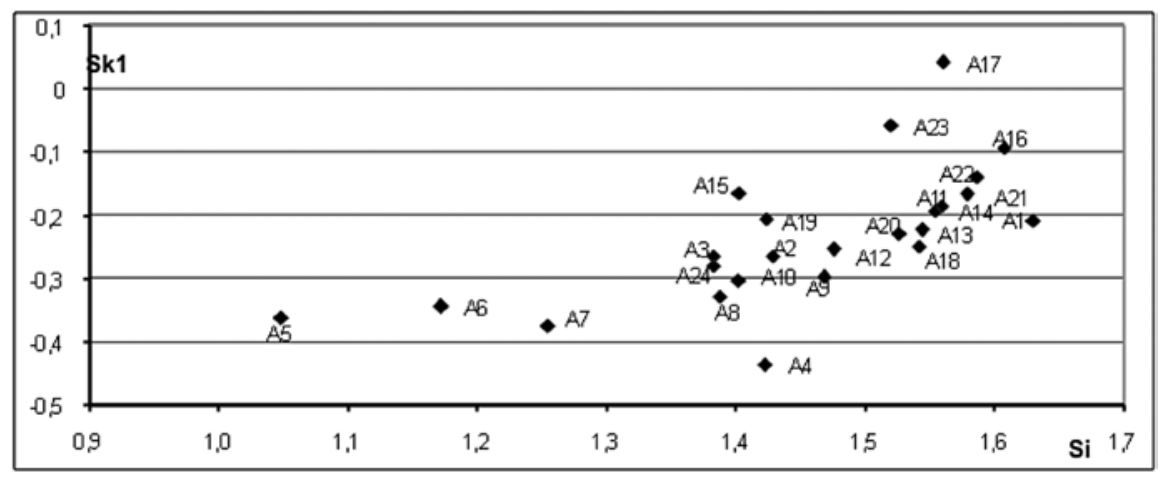

Fig. 10. Correlaciones entre asimetría y clasificación de las arenas en la Unidad 1. / Correlations between asymmetry and classification of sands in Unit 1.

La columna comienza con un episodio (Unidad 1.5) en el que la fracción gruesa es escasa y, cuando aparece, se trata de fragmentos de concreción y pequeños nódulos ferruginosos, con ausencia de caliza. Entre los gránulos, dominando los finos sobre los gruesos, aparecen materiales muy rodados aportados por el lenar. La fracción fina es arcillosa y se deposita por decantación. Nos encontraríamos en un momento húmedo, con episodios muy húmedos.

Le sigue un episodio (Unidad 1.4) en el que se produce el desprendimiento de coladas de las paredes. Esto hace que la fracción gruesa se incremente en fragmentos de concreción. Hay pequeños cantos y gránulos calizos. Se trataría de un momento menos húmedo, pero el más frío de la columna estudiada.

Estos dos momentos parece que se corresponden con el Solutrense lo que nos haría pensar en un clima cambiante con momentos frescos.
Para el resto de la columna estudiada, en el que incluiríamos el Magdaleniense y el Epipaleolítico, no hay grandes diferencias. Todo el sedimento se deposita en un periodo templado y húmedo que permite el aporte de materiales del lenar. El proceso predominante ha sido la decantación. La humedad parece haber sido mayor en el Magdaleniense (Unidad 1.3) y va disminuyendo en el Epipaleolítico para volver a aumentar en los niveles superiores.

\subsubsection{Columna B}

En las tablas 3 y 4 se presentan los resultados del análisis del laboratorio para la granulometría global (Tabl. 3) y para la granulometría de arenas e índices estadísticos (Tabl. 4) de la Columna B.

\begin{tabular}{|c|c|c|c|c|c|c|c|c|c|c|c|}
\hline & & $\mathbf{z}$ & canto & Gran grs & Gran fn & $\begin{array}{c}\% \\
>2 \mathrm{~mm}\end{array}$ & $\begin{array}{c}\% \\
<2 \mathrm{~mm}\end{array}$ & $\begin{array}{c}\% \\
\text { arenas }\end{array}$ & $\begin{array}{c}\% \\
\text { limos }\end{array}$ & $\begin{array}{c}\% \\
\text { arcillas }\end{array}$ & $\begin{array}{c}\text { Q50 } \\
<2 \mathrm{~mm}\end{array}$ \\
\hline \multirow{2}{*}{ U-2.1 } & B1 & 187 & 9 & 6,6 & 5,4 & 21 & 79 & 31 & 39 & 30 & 0,016 \\
\hline & B2 & 190 & 8 & 5 & 4 & 17 & 82 & 27 & 48 & 25 & 0,018 \\
\hline \multirow{4}{*}{ U-2.2 } & B3 & 199 & 4 & 2,7 & 2,1 & 9 & 91 & 22 & 48 & 30 & 0,013 \\
\hline & B4 & & 2 & 1,4 & 1,6 & 5 & 95 & 25 & 44 & 31 & 0,017 \\
\hline & B5 & & 0,3 & 0,2 & 0,9 & 1,3 & 99 & 27 & 37 & 36 & 0,011 \\
\hline & B6 & 211 & 14 & 0,9 & 0,4 & 15 & 84 & 20 & 32 & 48 & 0,003 \\
\hline \multirow{2}{*}{$U-2.3$} & B7 & 214 & 22 & 3,7 & 2,1 & 28 & 72 & 28 & 38 & 34 & 0,007 \\
\hline & B8 & 216 & 17 & 2,4 & 3 & 22 & 78 & 30 & 40 & 30 & 0,01 \\
\hline U-2.4 & B9 & 222 & 0,0 & 0 & 0,3 & 0,3 & 100 & 24 & 42 & 34 & 0,008 \\
\hline \multirow{3}{*}{ U-2.5 } & B10 & 231 & 45 & 1,4 & 1,3 & 48 & 53 & 28 & 38 & 34 & 0,01 \\
\hline & B11 & & 25 & 6,1 & 1,7 & 33 & 68 & 26 & 39 & 35 & 0,01 \\
\hline & B12 & 238 & 10 & 3,3 & 1,7 & 15 & 85 & 23 & 36 & 41 & 0,005 \\
\hline \multirow{3}{*}{ U-2.6 } & $\mathrm{B} 13$ & 249 & 0 & 0,1 & 0,4 & 1 & 99 & 26 & 33 & 41 & 0,011 \\
\hline & B14 & & 0 & 0 & 0,3 & 0,3 & 100 & 27 & 35 & 38 & 0,012 \\
\hline & B15 & 267 & 0 & 0,1 & 0,6 & 1 & 99 & 17 & 32 & 51 & 0,002 \\
\hline
\end{tabular}

Tabl. 3. Granulometría global Columna B. / Granulometry of the Column B. 


\begin{tabular}{|c|c|c|c|c|c|c|c|c|c|c|c|c|c|}
\hline & & & & & \multicolumn{3}{|c|}{ Arena } & \multicolumn{2}{|c|}{$\mathrm{mm}$} & \multicolumn{4}{|c|}{ Folk y Word } \\
\hline & & Z & $\begin{array}{c}\% \\
\text { fino }\end{array}$ & $\begin{array}{c}\% \\
\text { arena }\end{array}$ & $\begin{array}{c}\% \\
\text { grues }\end{array}$ & $\begin{array}{c}\% \\
\text { med }\end{array}$ & $\begin{array}{l}\% \\
\text { fin }\end{array}$ & So & Q50 & $\mathrm{Mz}$ & $\mathrm{Si}$ & Sk1 & K \\
\hline \multirow{2}{*}{$\begin{array}{l}\text { U- } \\
2.1\end{array}$} & B1 & 187 & 79 & 31 & 28 & 20 & 52 & 2,54 & 188 & 2,11 & 1,67 & $-0,25$ & 0,74 \\
\hline & B2 & 190 & 82 & 27 & 29 & 20 & 51 & 2,58 & 196 & 2,08 & 1,66 & $-0,23$ & 0,73 \\
\hline \multirow{4}{*}{$\begin{array}{l}\text { U- } \\
2.2\end{array}$} & B3 & 199 & 91 & 22 & 18 & 18 & 64 & 2,14 & 130 & 2,58 & 1,48 & $-0,4$ & 0,86 \\
\hline & B4 & & 95 & 25 & 20 & 22 & 58 & 2,17 & 160 & 2,36 & 1,53 & $-0,31$ & 0,87 \\
\hline & B5 & & 99 & 27 & 16 & 24 & 60 & 1,97 & 156 & 2,49 & 1,37 & $-0,27$ & 0,93 \\
\hline & B6 & 211 & 84 & 20 & 13 & 25 & 62 & 1,80 & 156 & 2,58 & 1,27 & $-0,21$ & 1,02 \\
\hline \multirow{2}{*}{$\begin{array}{l}\text { U- } \\
2.3\end{array}$} & B7 & 214 & 72 & 28 & 23 & 24 & 53 & 2,06 & 164 & 2,19 & 1,53 & $-0,37$ & 0,93 \\
\hline & B8 & 216 & 78 & 30 & 18 & 24 & 58 & 2,03 & 164 & 2,40 & 1,42 & $-0,27$ & 0,91 \\
\hline $\begin{array}{l}\text { U- } \\
2.4\end{array}$ & B9 & 222 & 100 & 24 & 12 & 22 & 66 & 1,87 & 140 & 2,66 & 1,27 & $-0,27$ & 0,91 \\
\hline \multirow{3}{*}{$\begin{array}{l}\text { U- } \\
2.5\end{array}$} & B10 & 231 & 53 & 28 & 19 & 23 & 58 & 2,05 & 164 & 2,36 & 1,47 & $-0,28$ & 0,90 \\
\hline & B11 & & 68 & 26 & 19 & 22 & 60 & 2,07 & 156 & 2,42 & 1,49 & $-0,3$ & 0,89 \\
\hline & B12 & 238 & 85 & 23 & 18 & 20 & 62 & 2,15 & 150 & 2,48 & 1,48 & $-0,3$ & 0,85 \\
\hline \multirow{3}{*}{$\begin{array}{l}\text { U- } \\
2.6\end{array}$} & B13 & 249 & 99 & 26 & 6 & 20 & 74 & 1,66 & 120 & 2,94 & 1,04 & $-0,25$ & 0,96 \\
\hline & $\mathrm{B} 14$ & & 100 & 27 & 6 & 23 & 71 & 1,70 & 125 & 2,87 & 1,09 & $-0,23$ & 0,89 \\
\hline & B15 & 267 & 99 & 17 & 7 & 19 & 75 & 1,65 & 120 & 2,96 & 1,07 & $-0,26$ & 1,04 \\
\hline
\end{tabular}

Tabl. 4. Granulometría de arenas e índices estadísticos. Columna B. / Sand sized sediment distribution and statistical analysis. Column B.

\section{Análisis e interpretación de los resultados.}

\section{Unidad 2.1 y Unidad 2.2: Muestras $B 1(Z=187)$ a $B 6(Z=211)$.}

Fracción gruesa.- La fracción gruesa es muy escasa y, en gran parte (33 a 40\%), está formada por aportes del lenar. Excepcionalmente la muestra B6 eleva el porcentaje de esta fracción por la presencia de un solo canto calizo de $6 \mathrm{~cm}$ de diámetro, así como las muestras B1 y B2 por los fragmentos de un suelo estalagmítico que sella la superficie de esta unidad, y de costras de concreción que recubren otros materiales. Aparece algún canto calizo de pequeño tamaño, poco o nada rodado, pero bastante alterado. En los gránulos, muy escasos, predomina también la concreción, aunque encontramos gránulos ferruginosos, además de lutitas y alguna caliza. Los más numerosos se encuentran en la unidad 2.1 y son de nuevo fragmentos de concreción de aspecto botroidal y superficie filamentosa que H. Laville (1975) llama por su aspecto en "chou-fleur" y que hace corresponder con momentos algo más cálidos. Los gránulos finos son más numerosos que los gruesos y presentan los mismos materiales.

Fracción fina.- La matriz presenta un color marrón amarillento oscuro: 10YR4/6. Es muy abundante y se clasifica como franco arcillosa, exceptuando la muestra B6 con un alto contenido de arcillas. En el calibre arenas, predominan las finas (Fig. 11 y 12). En las muestras superficia- les el contenido en arenas gruesas es bastante alto (Tabl. 4), lo que hace que el valor de la mediana, Q50, sean los más elevados de toda la columna. La Mz también es de las más bajas (2,11 y 2,08 ф). En general, la clasificación es mala, estando los valores de desviación más altos en las muestras con mayor contenido en arenas gruesas. La asimetría negativa nos indica una mejor clasificación en las arenas finas, con una cola de materiales más gruesos que están bien representados en las muestras más superficiales.

Todo esto nos hace pensar en un flujo no muy potente, pero prolongado en el tiempo, que arrastra gránulos finos de nódulos ferruginosos y lutitas muy rodadas, así como arenas gruesas, produciendo momentos de encharcamiento de aguas turbias que han decantado abundantes materiales finos.

Unidad 2.3: Muestras B7 $(Z=214)$ y B8 $(Z=216)$. Materiales gruesos de concreción se encuentran englobados en una matriz arcillosa marrón amarillenta (10YR5/8). Da la impresión de que los materiales han sufrido cierto arrastre; aparecen algo rodados.

Fracción gruesa.- La fracción gruesa es abundante (28\%). Entre los cantos, encontramos abundantes fragmentos de concreción y numerosos cantos calizos de pequeño tamaño $(1 \mathrm{a} 4 \mathrm{~cm})$ con forma de plaquetas, entre bastante o muy alteradas $(I A=45$ a 78$)$ y bastante rodadas, tal vez más por la alteración que por la rodadura. Entre los gránulos, también abundan las concre- 
Fig. 11. Curvas de granulometría fracción fina representativas de la Unidad 2. / Fine fraction distribution curve for Unit 2.

Fig. 12. Curvas de la fracción arena representativas de la Unidad 2. / Sand fraction distribution curve for Unit 2.
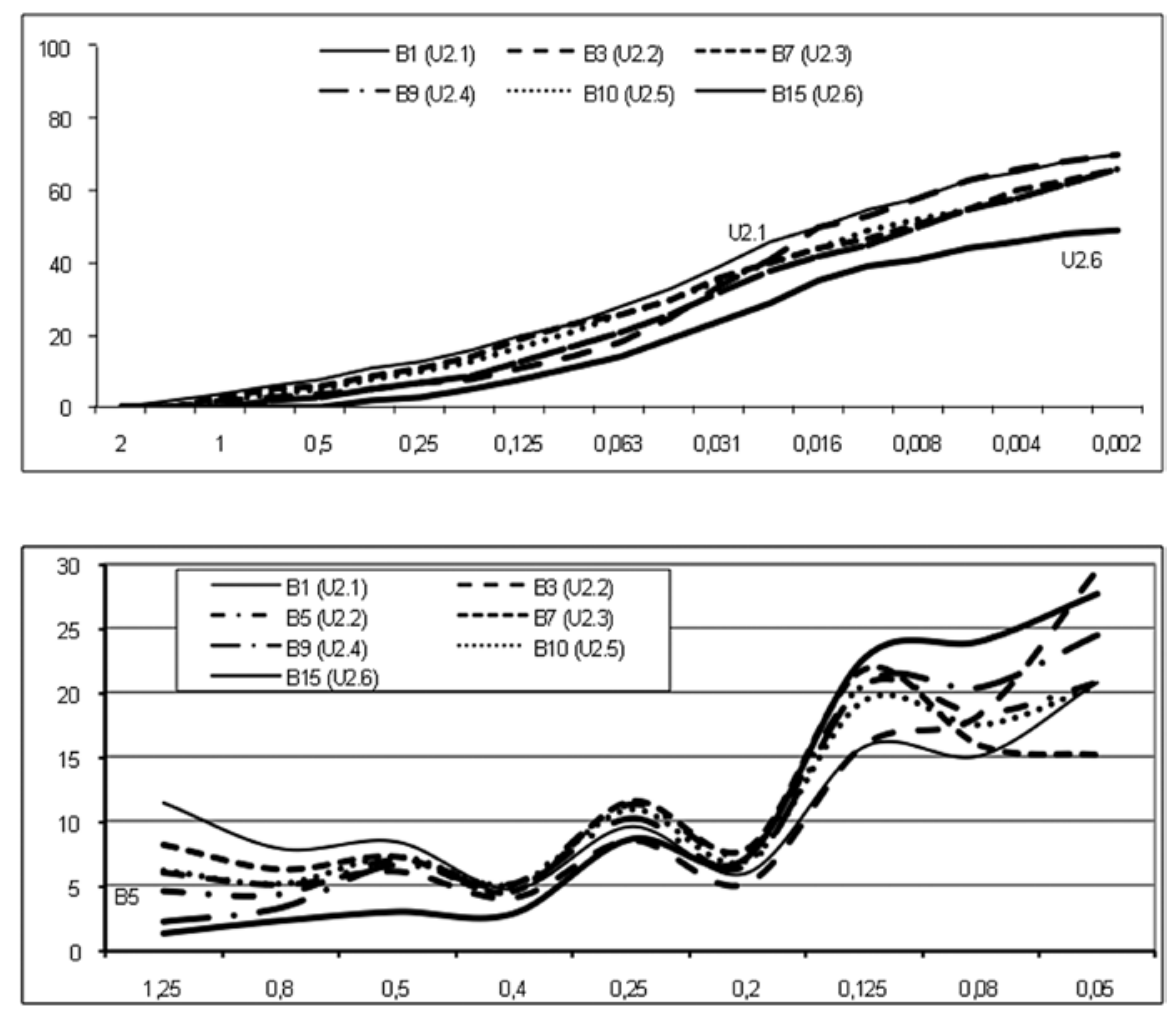

ciones; se ven calizas y aparece alguna lutita y nódulos ferruginosos. En general hay muy pocos materiales aportados por el lenar (0,34 a $1 \%$ del sedimento).

Fracción fina.- La matriz es abundante. Hay un predominio de limos y arcillas con un tercio de arenas. Dentro de las arenas, predominan las finas. La mediana y la media tienen valores elevados en la columna estudiada, semejantes a los obtenidos para las muestras B1 y B2 (Tabl. 4). La clasificación es mala con un valor de desviación alto con respecto a los valores calculados en la columna. La asimetría negativa vuelve a indicarnos una mejor clasificación en las arenas finas, presentando la distribución una cola hacia las arenas gruesas. Se observa un máximo para el calibre 0,125, menos acusado en B8.

El clima parece responder a un periodo fresco y algo húmedo.

\section{Unidad 2.4: Muestra B9 ( $Z=222)$.}

Fracción gruesa.- La fracción gruesa es muy escasa y se reduce a unos pocos gránulos finos. Entre estos se ven pequeños fragmentos de concreción y nódulos ferruginosos, todos ellos muy rodados.

Fracción fina.- La matriz, de color marrón amarillento (10YR5/8), está integrada por limos (42\%), arcillas (34\%) y dentro de las arenas, predominan también las finas (58\%).

Mediana y media se sitúan dentro del tamaño arenas finas. La clasificación, dentro de la columna, es intermedia con un valor de desviación de 1,27 que la diferencian de las muestras supra e infrayacentes. La asimetría sigue siendo negativa pero no tan elevada como la calculada para otras muestras de la columna.

El proceso dominante en la deposición de este nivel ha sido la decantación de materiales muy finos. No hay calibres mayores de $2 \mathrm{~mm}$, siendo los aportes del lenar muy escasos. Se puede interpretar como un episodio algo más templado y húmedo, pero con una escorrentía de muy baja potencia.

Unidad 2.5: Muestras B10 $(Z=231)$ a B12 $(Z=238)$. Segundo momento de acumulación de materiales gruesos.

Fracción gruesa.- Abundante sobre todo en B10 y B11 (47-32-15\%). Los cantos, en su mayoría de caliza (4124-8\%), son de pequeño y mediano tamaño, más pequeños en B12. Se encuentran bastante alterados (IA = 60 a 80) y sus aristas están algo redondeadas (ID=30 a 50); este desgaste puede estar facilitado por la corrosión. También se ha observado alguna concreción, pero en muy pequeño porcentaje. En los gránulos se ven estos mismos materiales. Únicamente en los finos aparecen otras litologías como cuarcitas y nódulos ferruginosos. Estos pequeños gránulos ferruginosos, así como los pequeños nódulos encontrados entre las arenas gruesas (también en proporción elevada, 50\% en B12), se encuentran bastante rodados. Los materiales aportados por el lenar en las tres muestras son abundantes, aunque de pequeño calibre. 
Fracción fina.- La matriz es escasa en B10 y B11 (53 y $68 \%)$ y más abundante en B12 (85\%). Su color es similar al de la Unidad 2.4 al igual que el resto de sus parámetros: predominan los limos y arcillas, así como las arenas finas. Las curvas de granulometría de la fracción fina son bastante tendidas. Se encuentran moderadamente clasificadas dentro de la columna con valores de asimetría negativos y relativamente elevados (Tabl. 4).

Las tres muestras se pueden englobar en un momento frío, aumentando hacia el techo de la unidad (B10). La humedad ha sido abundante con una escorrentía de flujo suave y de amplio recorrido que deposita materiales finos por decantación de aguas turbias.

\section{Unidad 2.6: Muestras B13 $(Z=249)$ a B15 $(Z=267)$.}

Fracción gruesa.- Los escasos materiales son de tamaño gránulo fino entre los que se encuentran numerosos nódulos ferruginosos bastante rodados.
Fracción fina.- La práctica totalidad del sedimento está compuesto por materiales menores de $2 \mathrm{~mm}$ : arcilla marrón amarillenta (10YR5/6), con un contenido en arenas de sólo el 20\%. De entre estas, las arenas finas son las más abundantes, lo que hace que mediana y media se sitúen en tamaños muy finos. Son las muestras mejor clasificadas de todas las estudiadas en esta columna. La asimetría es negativa pero no tiene valores tan elevados.

Esta unidad se sedimentó en un momento húmedo que permite la decantación de materiales muy finos.

Cuando relacionamos los parámetros estadísticos obtenidos en las arenas de las diferentes muestras vemos que todas se agrupan en una nube de puntos que demuestran que no ha habido diferencias en los procesos de la sedimentación de las arenas. Sólo las muestras B1 y B2 (Unidad 2.1); B7 (Unidad 2.2) y B13, B14 y B15 (Unidad 2.6) se separan del comportamiento general y forman grupos diferenciados también entre sí (Fig. 13).

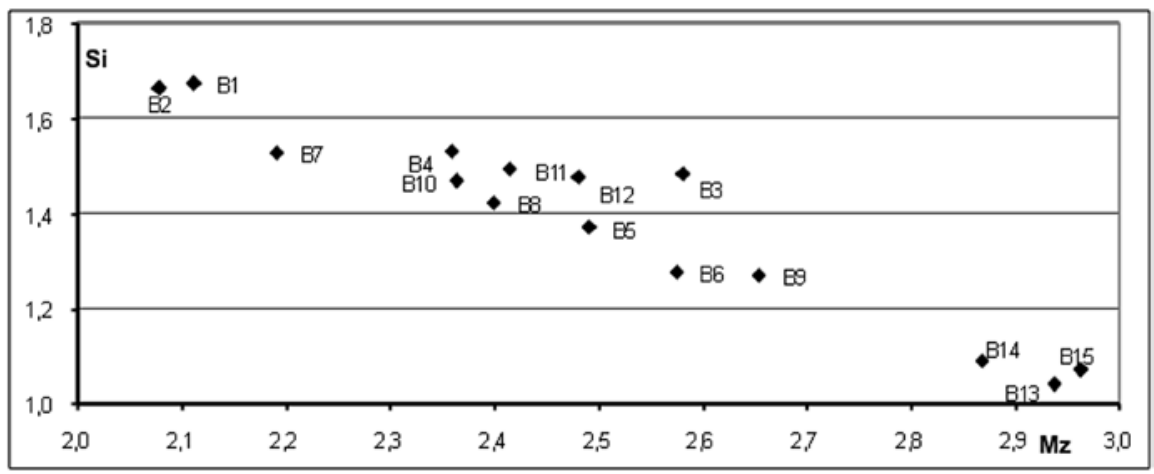

Fig. 13. Curvas de granulometría fracción fina representativas de la Unidad 1. / Fine fraction distribution curves for Unit 1.

\section{Conclusiones de la Columna B}

La base de la columna estudiada, Unidad 2.6, corresponde a un período templado y húmedo, con escorrentía muy débil que decanta aguas turbias.

Se superponen sedimentos que atestiguan un clima frío, aumentando hacia el techo con humedad alta y una escorrentía que deposita materiales no organizados de diversos calibres. Le sigue un periodo breve de atemperamiento con suave escorrentía, Unidad 2.4. Un nuevo empeoramiento sucede en la Unidad 2.3 con un clima frío y algo húmedo. A partir de este momento se produce un largo periodo de atemperación climática y sedimentación predominante de materiales finos en procesos de decantación, con una mayor energía a medida que nos acercamos a techo de la Unidad 2.2 y que persiste en la Unidad 2.1 en la que la escorrentía es capaz de arrastrar materiales de calibre algo mayor (ver tabla de correlaciones, Fig. 13). Toda esta columna ha quedado sellada por un suelo estalagmítico formado en un momento húmedo y templado.

\subsubsection{Muestreo C}

Estas muestras se han recogido en diferentes zonas de la cavidad, en la primera sala interior, en el final del pa- sillo que da acceso a la sala y por último en el arranque a la segunda sala interior, y no constituyen una verdadera columna sedimentológica. En las tablas 5 y 6 se presentan los resultados del análisis del laboratorio para la granulometría global (Tabl. 5) y para la granulometría de arenas e índices estadísticos (Tabl. 6) del muestreo C.

\section{Análisis e interpretación de los resultados}

La matriz de todas estas muestras es arcillosa o franco arcillosa y presenta un color marrón amarillento (10YR 5/4 a 6).

Unidad 3.1. Muestras C1 y C2. Se han recogido al final del pasillo entre el vestíbulo y la primera sala.

Fracción gruesa.- Es más abundante en la muestra C1 y está formada por pequeños cantos calizos muy degradados (7\%). Próximo a este lugar había un hogar rodeado de cantos que no aparecieron en otras zonas. El resto de materiales lo constituyen algún nódulo ferruginoso de tamaño canto y muchos más de calibre gránulo, entre los que encontramos también fragmentos de concreción y aportes del lenar en forma de cuarcitas y lutitas planares (Tabl. 5). En C2 se repiten los ma- 


\begin{tabular}{|c|c|c|c|c|c|c|c|c|c|c|c|c|}
\hline & & Cuadrícula & $\mathbf{Z}$ & cantos & Gran grs & $\begin{array}{c}\text { Gran } \\
\mathrm{fn}\end{array}$ & $\begin{array}{c}\% \\
>2 \mathrm{~mm} \\
\end{array}$ & 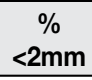 & $\%$ arenas & $\%$ limos & $\%$ arcillas & $\begin{array}{c}\text { Q50 } \\
<2 \mathrm{~mm} \\
\end{array}$ \\
\hline \multirow{2}{*}{ U-3.1 } & C1 & $8 C^{\prime}$ & 328 & 8 & 3,3 & 8.4 & 20 & 80 & 39 & 25 & 36 & 0,016 \\
\hline & $\mathrm{C} 2$ & $8 \mathrm{~B}^{\prime}$ & 316 & 1 & 3,4 & 4.7 & 9 & 91 & 37 & 28 & 35 & 0,019 \\
\hline \multirow{4}{*}{ U-3.2 } & C3 & \multirow{4}{*}{$18 \mathrm{E}^{\prime}$} & \multirow[t]{3}{*}{337} & 0 & 0 & 1 & 1 & 99 & 21 & 31 & 48 & 0,003 \\
\hline & C4 & & & 9 & 0 & 1 & 10 & 90 & 23 & 29 & 48 & 0,003 \\
\hline & $\mathrm{C5}$ & & & 0 & 0 & 0,4 & 0 & 100 & 24 & 33 & 43 & 0,006 \\
\hline & C6 & & 348 & 0 & 0 & 0,2 & 0 & 100 & 23 & 27 & 50 & 0,002 \\
\hline \multirow{2}{*}{ U-3.3 } & $\mathrm{C} 7$ & \multirow{2}{*}{$8 F^{\prime}$} & 338 & 19 & 4 & 3 & 26 & 74 & 27 & 35 & 38 & 0,007 \\
\hline & C8 & & 342 & 12 & 0,7 & 2,6 & 15 & 85 & 33 & 33 & 34 & 0,014 \\
\hline \multirow{3}{*}{ U-3.4 } & $\mathrm{C9}$ & \multirow{3}{*}{ 10J' } & 343 & 6 & 0,9 & 1,9 & 9 & 91 & 29 & 29 & 42 & 0,005 \\
\hline & $\mathrm{C} 10$ & & 353 & 6 & 1 & 2 & 9 & 91 & 26 & 29 & 45 & 0,006 \\
\hline & C11 & & 375 & 0 & 0 & 0,2 & 0 & 100 & 16 & 43 & 41 & 0,006 \\
\hline
\end{tabular}

Tabl. 5. Granulometría global Muestreo C. / Granulometry of the Sampling C.

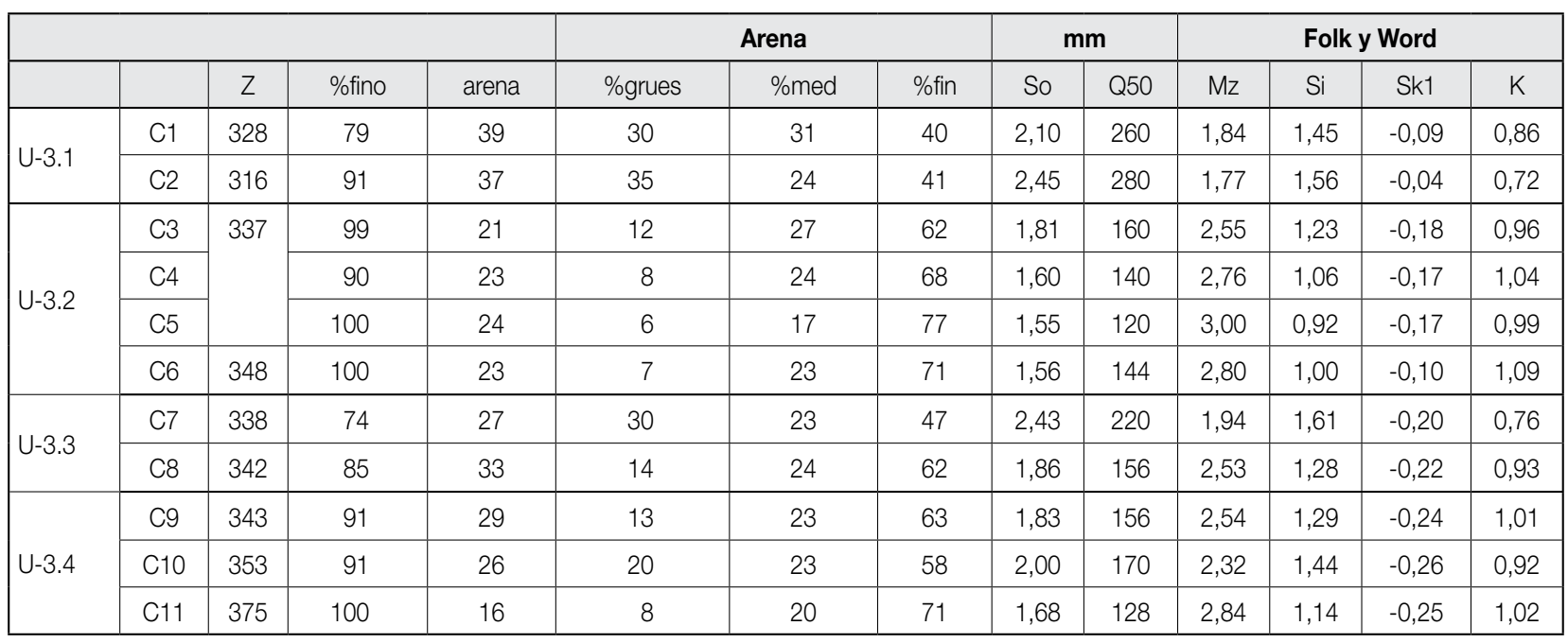

Tabl. 6. Granulometría de arenas e índices estadísticos. Muestreo C. / Grit sand and statistical indices. Sampling C.

teriales aunque en menor cantidad y no hay calizas. En ambas muestras todos estos materiales se encuentran muy rodados, predominando los calibres más finos.

Fracción fina.- El contenido en arenas es relativamente elevado predominando las gruesas a diferencia de otras muestras estudiadas en esta sala, dando una mala clasificación y curvas simétricas (Fig. 14 y 15).

Esta unidad se deposita en un momento muy húmedo, que arrastra materiales tamaño gránulo aportados por el lenar. Posiblemente el estrechamiento en la zona del pasillo acelera el flujo y lo hace algo más activo, dando porcentajes más altos de gránulos y arenas gruesas.

Unidad 3.2. Muestras C3 a C6. Primera sala interior. Los arqueólogos lo adscriben al Magdaleniense Inferior.

Fracción gruesa.- La fracción gruesa está ausente a excepción de un canto calizo de mediano tamaño $(4-5 \mathrm{~cm})$ en la muestra C4.
Fracción fina.- Se considera arcillosa (50\% del sedimento) y forma un suelo muy compacto. En las arenas predominan también las de calibre fino (Fig. 15). Las muestras son todas iguales y aparecen próximas en los gráficos de correlación y únicamente C3 se separa algo del grupo (ver Fig. 16).

El proceso de sedimentación es un flujo lento que deposita materiales finos por decantación abundando las arcillas de decalcificación.

Unidad 3.3. Muestras C7 y C8. Primera sala interior junto a la pared oeste. Magdaleniense Inferior.

Fracción gruesa.- Entre los materiales mayores de 1 $\mathrm{cm}$ abundan los cantos calizos de pequeño tamaño que aparecen poco o nada rodados y bastante alterados. Presentan el aspecto de haber sido descamados por el frío y posteriormente alterados en el suelo. Además de las calizas, aparece alguna arenisca limonitizada y escasos nódulos ferruginosos. Los gránulos son muy 

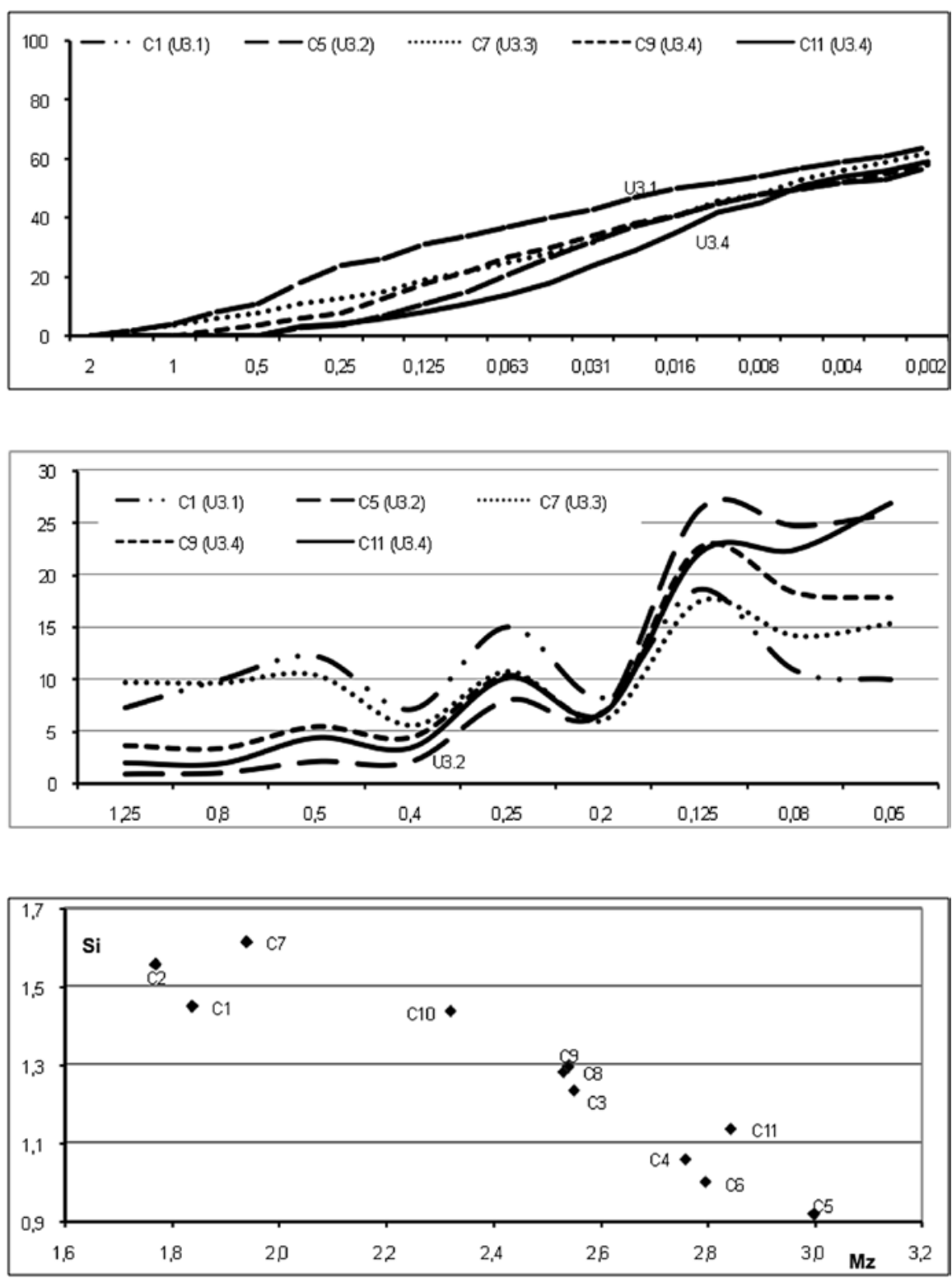

Fig. 14. Curvas de granulometría fracción fina representativas de la Unidad 3. / Fine fraction distribution curves for Unit 3.

Fig. 15. Curvas de la fracción arena representativas de la Unidad 3. / Sand fraction distribution curve for Unit 3.
Fig. 16. Correlaciones entre clasificación y calibre medio de las arenas en la Unidad 3. / Correlations between classification and average size of the sands in Unit 3. escasos y el material predominante es la caliza. Tanto en los gruesos como en los finos se observan también materiales aportados por el lenar como cuarcitas, areniscas, lutitas y, sobre todo nódulos ferruginosos. Sin embargo, mientras que en los gránulos gruesos sólo los nódulos ferruginosos aparecen rodados, en los gránulos finos las lutitas y gránulos cuarcíticos aparecen muy rodados. Esto nos hace pensar en un flujo tal vez de escasa potencia pero con un arrastre largo.

Fracción fina.- Observamos un equilibrio de arcillas, limos y arenas. Estas últimas son más abundantes con respecto a otras muestras de la sala interior $y$, entre ellas, las gruesas sobre todo en C7. Esto hace que los parámetros estadísticos se alejen de los obtenidos en C8 dando valores de media y mediana más elevados.
La clasificación es mala con un valor elevado de desviación, y presenta un valor negativo de asimetría. Es muy probable que nos encontremos ante muestras con una mezcla de episodios que han sido removidas; el valor de asimetría es alto, así como la clasificación. Parece que la proximidad de la pared es un paso preferente de escorrentía suave, que se hace más patente en la superficie, siendo la muestra más profunda la más arcillosa. Probablemente nos encontramos ante el mismo fenómeno que se dio en C1 y C2. Nos encontraríamos en un momento húmedo con fluctuaciones.

Unidad 3.4. C9 y C10. Inicio de la segunda sala interior. Epipaleolítico

Fracción gruesa.- Muy escasa en ambas muestras. En los cantos aparecen pequeños fragmentos de concre- 
ción, algún canto calizo de pequeño tamaño y pequeños nódulos ferruginosos que podrían considerarse gránulos. Tanto concreción como caliza aparecen muy alteradas y muy rodadas. En los gránulos abundan las concreciones y nódulos ferruginosos; materiales más variados en los gránulos finos que contienen bastantes lutitas y alguna cuarcita. La morfoscopía de gránulos finos y arenas gruesas confirma el alto grado de rodadura.

Fracción fina - Supera el 90\% del sedimento y presenta una textura arcillosa (40\%). En las arenas también predominan las más finas (Fig. 15). La asimetría vuelve a ser negativa y la clasificación mala. Estas dos muestras analizadas parecen indicar un flujo de amplio recorrido con una corriente laminar bastante mansa que decanta materiales muy finos.

La muestra C11 (Z=375) se recoge $20 \mathrm{~cm}$ por debajo de las dos anteriores (C9 y C10). Sin embargo, el proceso de sedimentación es muy semejante. No hay materiales gruesos, sólo escasos gránulos finos de los que un tercio aproximadamente son gránulos ferruginosos y el resto pequeños fragmentos de concreción. Fracción fina arcillo-limosa con predominio de arenas finas y limos, que superan el $50 \%$ del sedimento.

\section{Conclusiones del Muestreo C}

Como ya hemos dicho, este muestreo no forma una columna sedimentológica pero todas ellas parecen haberse depositado en un proceso condicionado por un clima húmedo con fluctuaciones más húmedas.

\subsubsection{Conclusiones de la sedimentología}

La superficie excavada es muy amplia y los niveles diferenciados en los diversos muestreos no tienen gran continuidad lateral, desapareciendo cuando pasamos a diferentes zonas de la cavidad. Sin embargo, intentamos relacionar, buscando afinidades, las muestras de las diferentes columnas para un mismo nivel arqueológico, teniendo siempre presente que el depósito está muy condicionado por el lugar que ocupa en la caverna.

\section{Muestras del Epipaleolítico:}

A5 a A11. El sedimento se deposita en un clima templado y húmedo. Se encuentran elementos aportados por el lenar y un predominio de materiales finos. La humedad parece disminuir de muro a techo de la unidad. En la base el flujo ha tenido cierta energía, al menos en algunos episodios, y ha sido capaz de transportar materiales de calibre gránulo y arena gruesa.

C9 y C10. Las dos muestras analizadas del Epipaleolítico parecen indicar un flujo de amplio recorrido con una corriente laminar bastante mansa que decanta materiales muy finos.
B5. La escorrentía parece no muy potente siendo los procesos de decantación de aguas turbias los dominantes.

\section{Posible Magdaleniense Superior-Final:}

C11. y B9. La decantación es el proceso dominante. Breve atemperamiento y suave escorrentía.

\section{Magdaleniense Inferior:}

A12 a A14. Se trata de un episodio templado y bastante húmedo, con energía suficiente para depositar materiales aportados por el lenar, aunque predominan los materiales depositados por decantación: arenas finas, limos y arcillas que componen una matriz franco arcillosa.

C1 a C7. En la zona más central de la cavidad los restos del Magdaleniense Inferior se depositan sobre un sedimento arcilloso depositado por aguas turbias de flujo muy lento en procesos de decantación. Junto a la pared la velocidad del flujo es algo mayor seguramente debido a un camino preferente del agua y encontramos materiales de mayor tamaño, más rodados y aportados desde el exterior por el lenar.

B10 y B11. Frío aumentando hacia techo con humedad alta y una escorrentía que decanta materiales revueltos.

\section{Solutrense:}

A17 y A18. En este episodio se produce el desprendimiento de coladas de las paredes. Esto hace que la fracción gruesa se incremente en fragmentos de concreción. Hay pequeños cantos y gránulos calizos. Se trataría de un momento menos húmedo, pero el más frío de la columna estudiada.

A19 a A23. La fracción gruesa sólo aparece en A21 y A22 (12\%) y se trata de fragmentos de concreción y pequeños nódulos ferruginosos. además de materiales aportados por el lenar, dominando los finos sobre los gruesos; se encuentran muy rodados. La fracción fina se deposita por decantación. Nos encontraríamos en un momento muy húmedo con episodios menos húmedos y templado con momentos más rigurosos.

C8. La muestra C8 presenta las características de C7, pero con menos fracción gruesa, y la que hay, es más pequeña, aunque también está rodada. La matriz es fina, y se clasifica como franco-arcillosa.

B15. Templado y húmedo. Escorrentía muy débil que decanta aguas turbias.

\subsubsection{Mineralogía de los sedimentos alóctonos}

Para la caracterización mineralógica de los sedimentos alóctonos finos (arcillosos- limosos) que rellenan con aproximadamente $2 \mathrm{~m}$ de serie estratigráfica la cueva de Praileaitz I, han sido muestreados un total de 17 puntos localizados en la parte alta de la serie estratigráfica (por 


\section{MUESTREO DEL SEDIMENTO DETRÍTICO}

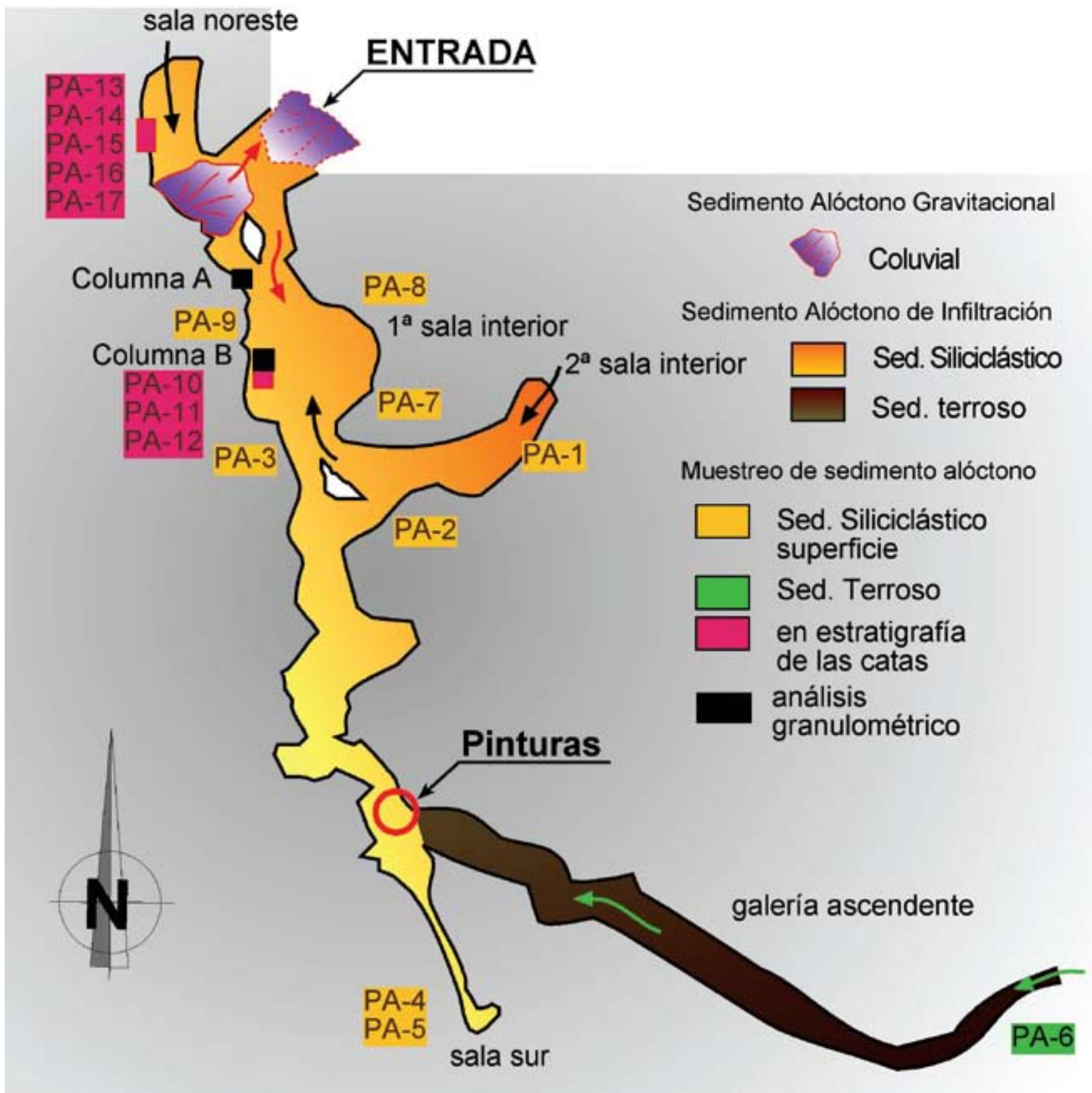

Fig. 17. Situación de los puntos de muestreo de sedimento detrítico en la Cueva de Praileaitz I. / Location of detrital sediment samples in the Praileaitz Cave I.

cuestiones de afloramiento) y en los cortes de las catas de excavación arqueológica. La información mineralógica obtenida junto con la ofrecida por los cantos centimétricos anteriormente descritos, nos pueden informan sobre el tipo de aporte y procedencia de los mismos.

De las 17 muestras estudiadas, 16 corresponden al nivel sedimentario siliciclástico que aflora desde la entrada hasta la sala sur y una muestra corresponde al sedi- mento terroso de la galería ascendente (Fig. 17). Estas muestras pertenecientes al nivel sedimentario alóctono de carácter siliciclástico, se agrupan en dos conjuntos de muestras que corresponden a distintos niveles estratigráficos: PA-10 al 12 y PA-13 al 17 fueron tomadas en las catas de excavación (Fig. 7, columna A). El resto pertenecen a la parte alta del relleno sedimentario que aflora tras la intervención arqueológica en ambas salas. 


\begin{tabular}{|c|c|c|c|c|c|c|c|c|}
\hline Muestra & $\% Q \mathbf{z}$ & $\%$ Calc & $\%$ Filos & $\%$ FdK & $\%$ Albita & $\%$ Illita & $\%$ Caolinita & $\%$ Vermiculita \\
\hline PA1 (Gours) & 14,6 & 0 & 85,4 & - & - & 73 & 15 & 12 \\
\hline PA6 & 56 & - & 40 & 2 & 2 & 58 & 21 & 21 \\
\hline PA2 & 56 & 1 & 41 & 1 & 1 & 71 & 14 & 15 \\
\hline PA3 & 52 & 0 & 48 & 1 & 2 & 83 & 13 & 4 \\
\hline PA7 & 71 & - & 26 & 1 & 2 & 65 & 24 & 11 \\
\hline PA8 & 63 & - & 34 & - & 3 & 63 & 23 & 14 \\
\hline PA10 & 51 & 5 & 41 & - & 3 & 68 & 21 & 11 \\
\hline PA11 & 55 & - & 42 & 3 & trazas & 66 & 22 & 12 \\
\hline PA12 & 60 & - & 35 & 2 & 3 & 67 & 23 & 10 \\
\hline PA13 & 66 & 0 & 34 & - & - & 72 & 14 & 14 \\
\hline PA14 & 66 & 1 & 28 & 2 & 3 & 74 & 14 & 12 \\
\hline PA15 & 47 & - & 48 & 2 & 3 & 74 & 15 & 11 \\
\hline PA16 & 62 & - & 33 & 2 & 3 & 70 & 20 & 10 \\
\hline PA17 & 55 & - & 40 & 3 & 2 & 74 & 17 & 9 \\
\hline PA4 & 53 & 0 & 47 & 1 & 2 & 74 & 16 & 10 \\
\hline
\end{tabular}

Tabl. 7. Análisis mineralógico "corregido" de los sedimentos endokársticos arcilloso-limosos de Praileaitz I. Las muestras están agrupadas por colores, según su localización (Fig. 17) (Rosa= sedimentos endokársticos muestreados en estratigrafía; Naranja = Sedimentos superficiales desde la entrada hasta la sala de las pinturas; verde = Sedimentos superficiales de la galería ascendente). / "Corrected" mineralogical analysis of the clayey-silty endokarstic sediments from Praileaitz cave I. The samples are grouped by colour, according to their location (Fig. 17) (Pink = sediments sampled on stratigraphy; Orange = surface sediments, from the entrance to the paintings room; Green = surface sediments from ascending gallery).

Al observar los resultados de los análisis mineralógicos de muestra total destacan, por un lado, la gran varianza de la proporción del calcita del sedimento y la homogeneidad de los grupos de filosilicatos predominantes, a excepción del PA-6 o sedimento terroso de la galería ascendente. La proporción de $\mathrm{CaCO}_{3}$ presente en el sedimento depende, en este caso, exclusivamente de la relación existente entre los sedimentos detríticos y químicos: la filtración de aguas saturadas en carbonato procedentes de los espeleotemas puede cementar parcialmente el sedimento, aportando más o menos calcita al medio. Si corregimos, por tanto, el contenido de calcita de los sedimentos por tratarse de un mineral incorporado durante la diagénesis (postsedimentario) observamos que tanto la mineralogía total de los sedimentos como la mineralogía de arcillas (filosilicatos) es muy homogénea (Tabl. 7). Es de destacar la presencia de goethita en todas las muestras analizadas.

PA-1 corresponde a las arcillas que tapizan los gours activos en la actualidad, situados al fondo de la segunda sala interior (Fig. 18), por lo que corresponde a la sedimentación subactual de la cueva. En los rellenos de los gours solamente se depositan las arcillas puras de decantación transportadas por el agua que, en el caso de Praileaitz I, están compuestas en un $86 \%$ por filosilicatos (illita en su mayoría $73 \%$ ), y algo de cuarzo (14\%). La abundancia de filosilicatos puede estar relacionada con la poca capacidad de transporte del agua (laminar), dado que el Cuarzo se concentra en las partículas de tamaño limo y arena. Este aporte detrítico puede proceder tanto del lavado de la roca caliza urgoniana (fracción insoluble), de la propia estratigrafía de la cueva como de lavado de los suelos del exterior.

En el resto de las muestras analizadas observamos que más del $50 \%$ de la muestra está compuesta por mineral de cuarzo y en torno al $30-40 \%$ de filosilicatos. La presencia de feldespato potásico y albita, pese a no tener ningún valor cuantitativo, nos indica la procedencia a partir de una roca madre siliciclástica.

En cuanto a la mineralogía de las arcillas (filosilicatos) la illita predomina en más de un $70 \%$. Es de origen claramente detrítico aportado, en parte, por la propia roca caliza, pero también trasportada desde las series siliclásticas del entorno por el agua. La caolinita, que ronda entre los $14-23 \%$, puede tener un origen detrítico (al igual que la illita) o ser producto de neoformación en suelos a partir de la disolución incongruente de feldespatos y albitas. La vermiculita es el tercer tipo de filosilicato que predomina en la fracción arcilloso-limosa de Praileaitz I, con una presencia en torno al 10-15\%. La homogeneidad que muestran los análisis mineralógicos de las estratigrafías estudiadas (cata de la primera sala interior y sala norte), nos indica la persistencia del área fuente de los sedimentos que se depositaron en la cueva de Praileaitz I, independientemente de las variaciones climáticas. 

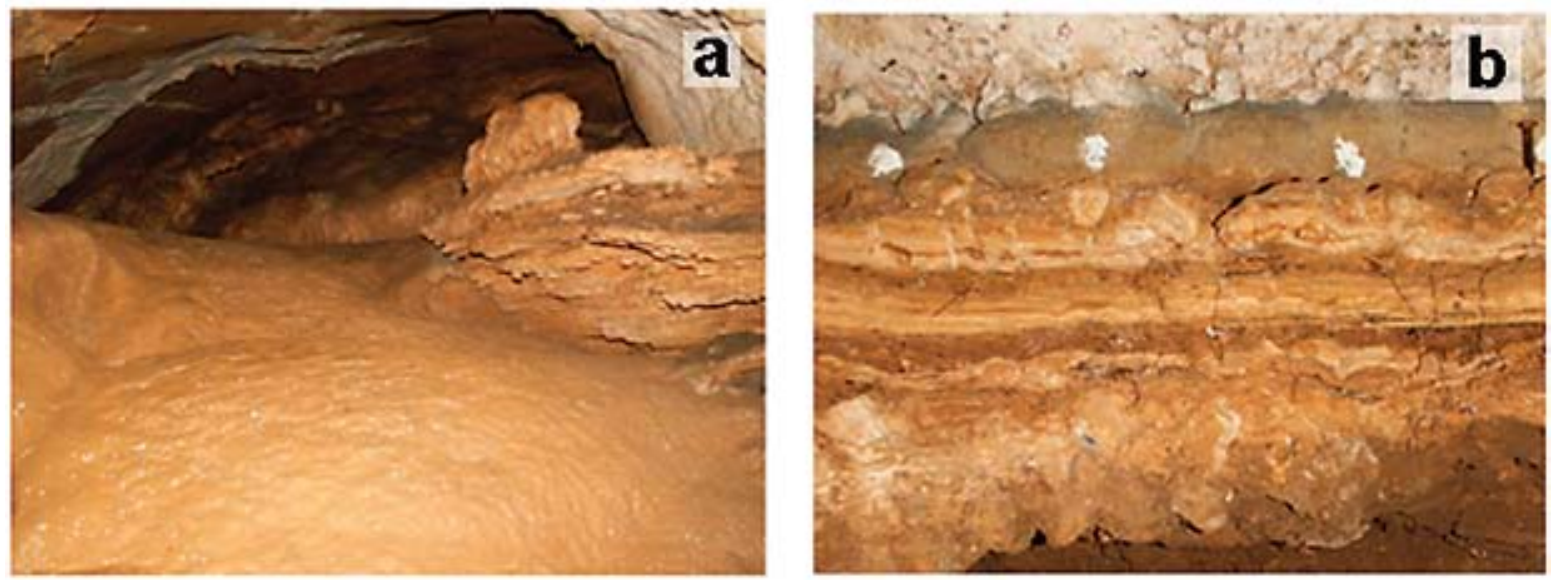

C
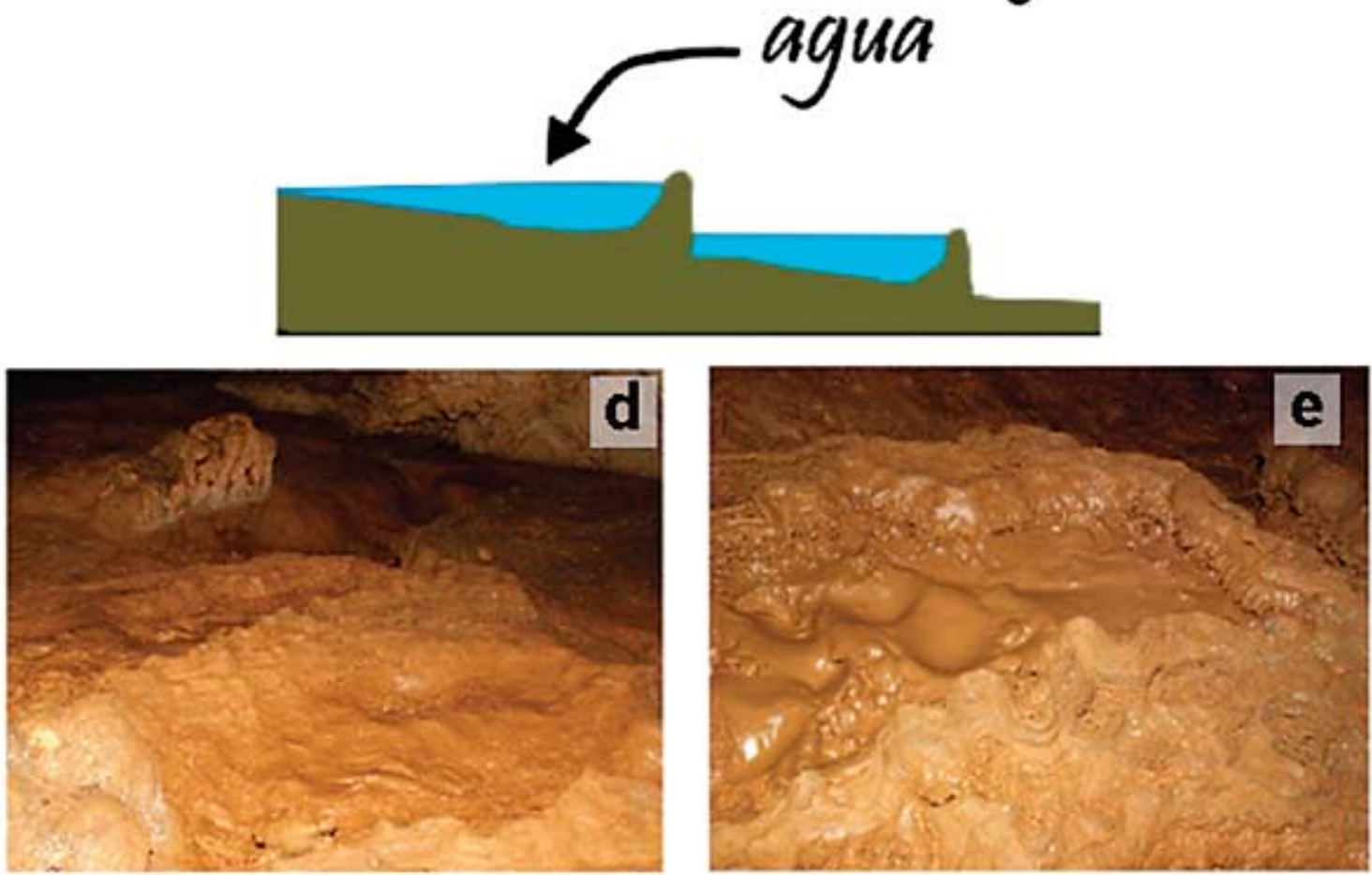

Fig. 18. Fotos de espeleotemas de flujo laminar ( $a$ y b) y gours (c, d y e). Es frecuente observar laminaciones o tapices de arcilla, producto de la decantación del material que transporta el agua en suspensión (PA-1). / Different types of laminar flow speleothems: flowstones ( $a$ and b) and gours (c, $d$ and e). Laminations or clay tapes are often seen, created by the decantation of the suspended material in water (PA-1).

Si observamos la mineralogía de los sedimentos detríticos terrosos que conforman el suelo de la galería ascendente, observamos que la composición mineralógica del sedimento apenas difiere del resto. La mineralogía de las arcillas, sin embargo, muestra una señal significativa con un porcentaje elevado relativo de la vermiculita frente a la illita (Tabl. 7). En la fracción arcilla, la vermiculita suele aparecer en numerosos tipos de suelos bajo diversas condiciones de alteración, desde las zonas polares a las tropicales, pasando por zonas templadas y subtropicales, en las que es de los minerales de arcilla más abundantes. En España, son comunes en los suelos que contie- nen considerable cantidad de micas (HERNANDO et al., 2001), pero no así en suelos desarrollados sobre calizas. Chiang et al. (1997), en suelos ácidos de bosques alpinos de Taiwan, identifican vermiculita y vermiculita con hidróxidos interlaminares a partir de areniscas y pizarras, dando como condiciones favorables para su formación un $\mathrm{pH}$ moderadamente ácido (4,6-5,8), frecuentes ciclos de humectación y sequía, bajo contenido en materia orgánica y condiciones oxidantes. La transformación de micas-illitas en vermiculita se realiza a través de interestratificados illita-vermiculita en suelos kársticos relativamente evolucionados (ARRIOLABENGOA et al., 2015). 


\subsubsection{Sedimentación química (espeleotemas)}

En el mundo de los espeleotemas destaca la diversidad de formas que pueden adquirir. Estas formas dependen del tipo de flujo de agua y de las fuerzas que actúan sobre él, pero pueden dividirse en subaéreos y subacuáticos. Dentro de cada grupo, dependiendo de la participación relativa de distintos factores físico-químicos, se producirán los diferentes tipos de espeleotemas, que distintos autores han clasificado morfológicamente. Es el caso del trabajo de Durán et al. (2000), en el que se inspira buena parte de lo que se expondrá a continuación. En la cueva de Praileaitz I destacan los formados en condiciones vadosas, a partir de goteo (Fig. 19) o flujo laminar.
Fig. 19. Fotos de espeleotemas de goteo: a) macarrones; b) forma mixta con crecimiento de macarrones sobre estalactitas; c) estalagmita coraliforme (lápiz) y lisa; d) columnas formadas por unión de estalactitas y estalagmitas. / Different types of drip water speleothems: a) macaroni; b) macaroni types on stalactites growth; c) coralline (pencil) and smooth stalagmite; d) columns formed by the union of stalactites and stalagmites.
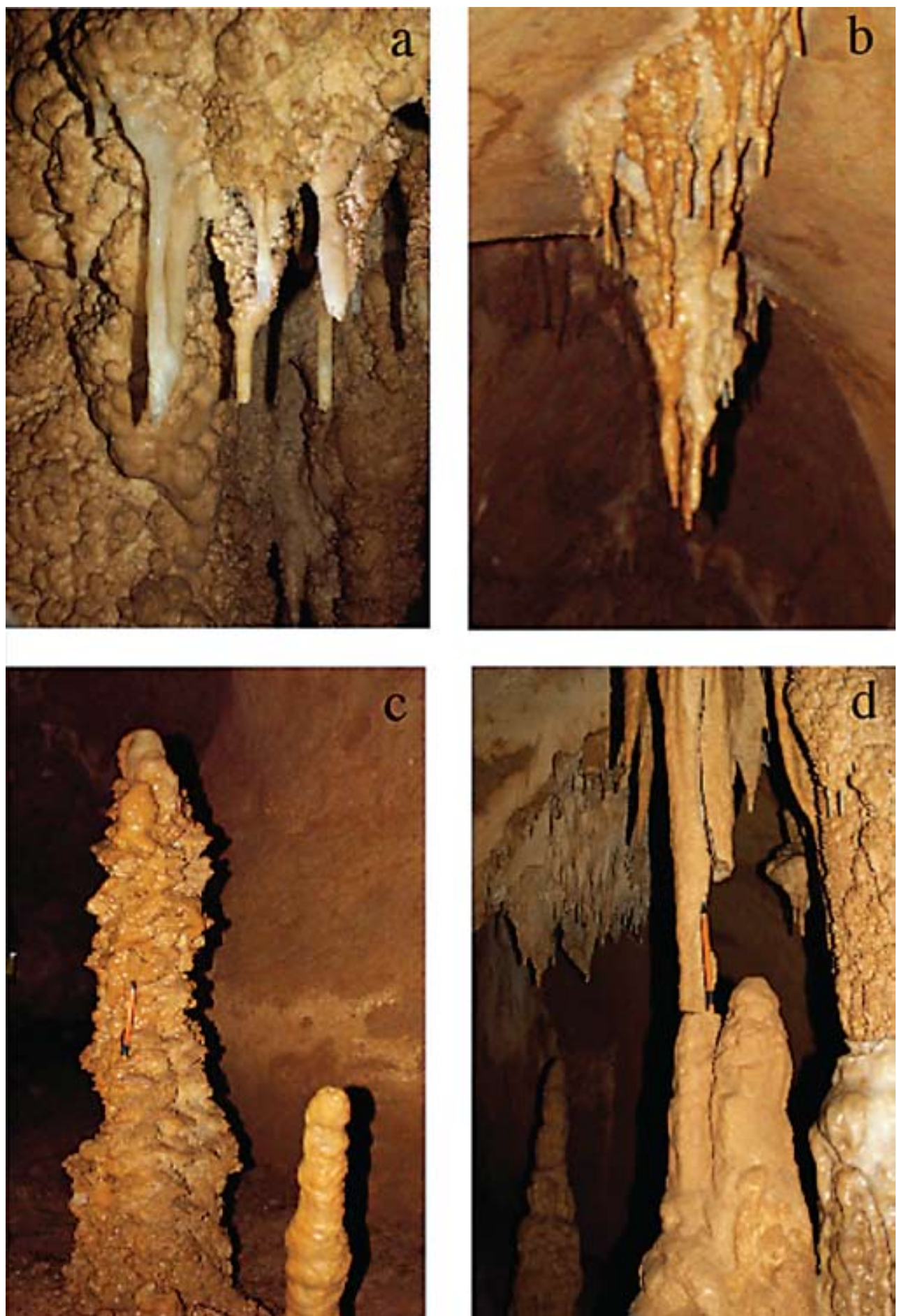

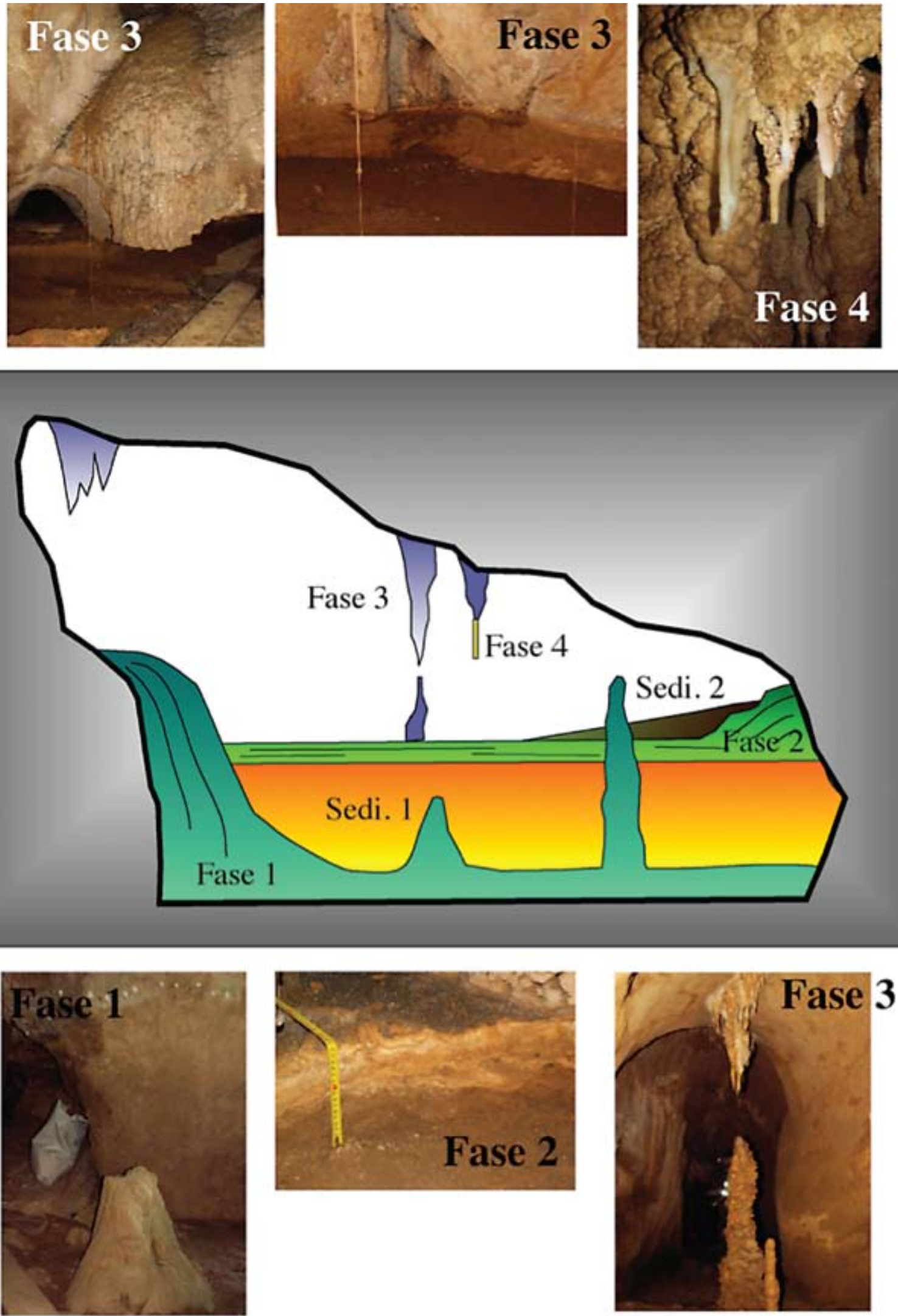

Fig. 20. Fases de crecimiento de espeleotemas e intercalaciones de sedimento detrítico. / Phases of speleothems growth and intercalations of detrital sediment. 


\section{Fases de formación de Espeleotemas}

La relación temporal entre las distintas formaciones de espeleotemas o la relación de éstas con la sedimentología revela, en una primera instancia y a falta de estudios más detallados, la existencia de, al menos, 4 eventos de formación (Fig. 20). En la zona de la entrada actual, el espeleotema de flujo en cascada y las estalagmitas se prolonga y asoman por debajo del tramo sedimentario detrítico rico en contenido arqueológico y fosilífero de edad
Magdaleniense. Estas formas podrían ser el ejemplo del primer evento de formación de espeleotemas (Fase 1). Algunos de los espeleotemas pertenecientes a esta fase muestran evidencias de erosión física, permitiendo observar la estratigrafía antigua con intercalaciones de material detrítico grueso (hasta $6 \mathrm{~cm}$ de diámetro máximo) entre las distintas láminas de espeleotema.

Siguiendo como nivel de correlación los sedimentos de edad Magdaleniense, a partir de la primera sala interior y hasta la Sala de las Pinturas, el nivel arqueológico
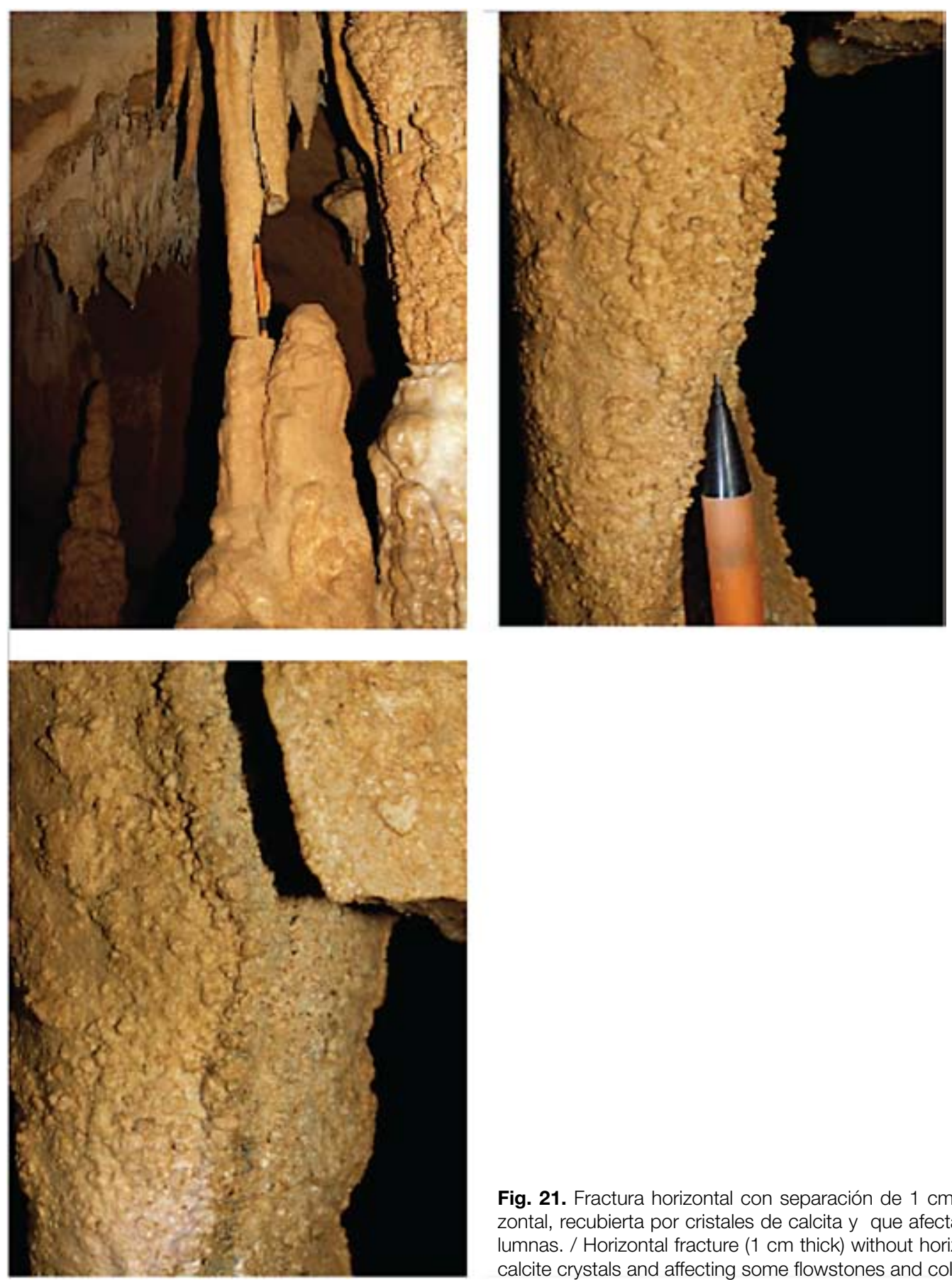

Fig. 21. Fractura horizontal con separación de $1 \mathrm{~cm}$ sin desplazamiento horizontal, recubierta por cristales de calcita y que afecta a algunas coladas y columnas. / Horizontal fracture $(1 \mathrm{~cm}$ thick) without horizontal scroll, covered with calcite crystals and affecting some flowstones and columns. 
está fosilizado por una costra de carbonato cálcico de 8 a $20 \mathrm{~cm}$ de grosor con gran profusión de gours en la superficie, que indican una dirección de paleoflujo hacia la entrada actual de la cueva (Fase 2). Por debajo de esta estratigrafía y gracias a las labores de excavación arqueológica afloran estalagmitas de la Fase 1, que se correlacionan con otra fase de colada, fuertemente erosionada y casi 1 metro por encima en cota del registro sedimentario de la cueva. Esta primera fase de formación de espeleotemas vadosos tuvo lugar desde antes de $350 \mathrm{ka}$, hasta aproximadamente $112 \mathrm{ka}$ (ARANBURU et al., 2015). Tanto en la primera como en la segunda sala interior hay varios ejemplos de estalagmitas, banderas y columnas que descansan sobre la costra anteriormente descrita (Fase 3), algunas de ellas datadas del Holoceno (VANGHI et al., 2015). La última fase de crecimiento de espeleotemas constituyen aquellos que actualmente están en fase de crecimiento (Fase 4).

Algunos de los espeleotemas que corresponden a la fase 2 o quizás 3 (coladas de la segunda sala interna y columna de la galería ascendente) muestran fracturas con separación de hasta $1 \mathrm{~cm}$. La razón de estas rupturas puede estar en el nivel de sedimentos infrayacente y en la pérdida de volumen de las arcillas por carga. Es de destacar que solamente están afectados los espeleotemas sujetos al substrato y no las estalactitas de la misma generación. Los cristales de calcita que recubren la superficie de ruptura son testigo del tiempo transcurrido, descartando su origen subactual (Fig. 21).

La formación de espeleotemas depende de factores particulares tales como la fuerza condicionante (gravedad o capilaridad), las características del flujo (caudal de agua, modo de circulación, la velocidad, quimismo), ubicación espacial, tipo de sustrato... Curiosamente, el equilibrio entre estos factores es altamente delicado. De este modo, cuando en una cueva se alteran las condiciones de equilibrio ambiental, como sucede con la alteración del medio físico del entorno de la cueva (excavaciones de la propia cueva, apertura de nuevas pistas, desmontes, ...) o la entrada descontrolada de visitantes, los espeleotemas pueden alterarse disolviéndose (por condensación de la humedad o cambios en el quimismo del agua) o pueden formarse nuevas precipitaciones de carbonato cálcico (debido al aumento de la temperatura).

\section{Degradación de espeleotemas}

En la cueva de Praileaitz I son evidentes los rasgos de deterioro que afectan tanto a la roca encajante como a espeleotemas de diversos tipos y generaciones (Fig. 22). El soporte de muchas de las pinturas (las banderas, concretamente) están en franco deterioro debido a la disgregación de la textura del espeleotema por disolución selectiva de cristales y creación de porosidad intercristalina. El producto resultante de las afecciones que prolifera en los distintos espeleotemas es la micritización: degradación de la textura original del cristal generando partículas inferiores a $4 \mu \mathrm{m}$. Algunas banderas, estalactitas y estalagmitas presentan un aspecto blanco y mate en su parte externa (en algunos casos con textura pulverulenta), y la parte interior la macroestructura es laminada y está definida por capas blancas que alternan con otras grises compactas y brillantes. Las capas blancas del interior son de la misma naturaleza que la parte exterior

Fig. 22. Espeleotemas en distinta fase de degradación por corrosión (C. Olaetxea). / Different types and stages of corrosion in speleothems (C. Olaetxea).
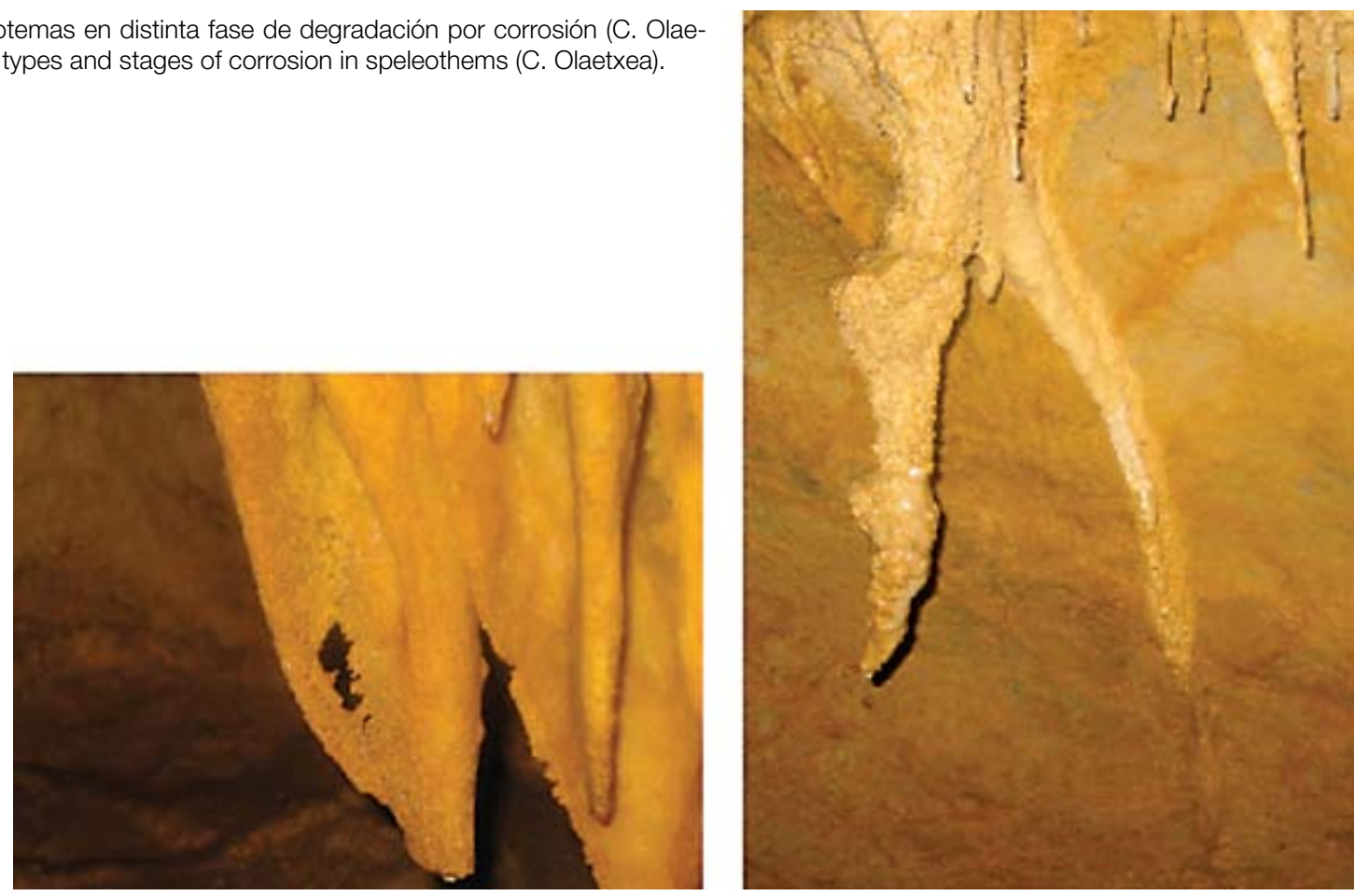
y en lámina delgada corresponden a zonas de aspecto micrítico con porosidad alta.

El proceso de micritización en la cueva de Praileaitz I afecta a casi todos los tipos de espeleotemas y con el objeto de realizar una primera aproximación al problema, se tomaron 2 muestras de espeleotemas: un fragmento de estalactita caído y un trozo de bandera $(<2 \mathrm{~cm}$.) totalmente pulverizado, ambos en la galería ascendente y correspondientes a la Fase 3 de formación de espeleotemas (Figs. 20 y 22).

\subsubsection{Estudio Hidrogeológico}

La atmósfera subterránea y las condiciones hidroquímicas de las aguas que se infiltran hacia el macizo kárstico se mantienen en un equilibrio con las condiciones naturales existentes. Cualquier acción antrópica que modifique las condiciones ambientales en las que se formó la cavidad y, por tanto, en las que se realizaron las pinturas podría provocar cambios irreversibles.
Estas modificaciones del uso del territorio, como desbrozado de la cobertera vegetal, construcción de vías por encima de la cavidad, abertura de nuevas vías de entrada a las cavidades, disminución del área de infiltración del agua de lluvia hacia la cavidad, entre otros, deben estudiarse mediante un seguimiento en detalle de los parámetros ambientales de la atmósfera de la cavidad y del quimismo de las aguas, lo que permitiría reconocer si existe afección a la cueva y, por tanto, a las pinturas, y el grado para establecer mecanismos de protección.

\section{Resultado de parámetros ambientales}

Los parámetros ambientales de la atmósfera subterránea (temperatura, humedad relativa y concentración de $\mathrm{CO}_{2}$ ) han sido recopilados con un dispositivo Vaisala GM70 acoplado a los sensores HMP45 para las medidas de humedad y temperatura y GMP221 para la medida de concentración de $\mathrm{CO}_{2}$ en el aire. Este dispositivo, instalado en la Sala de las Pinturas, ha permitido realizar

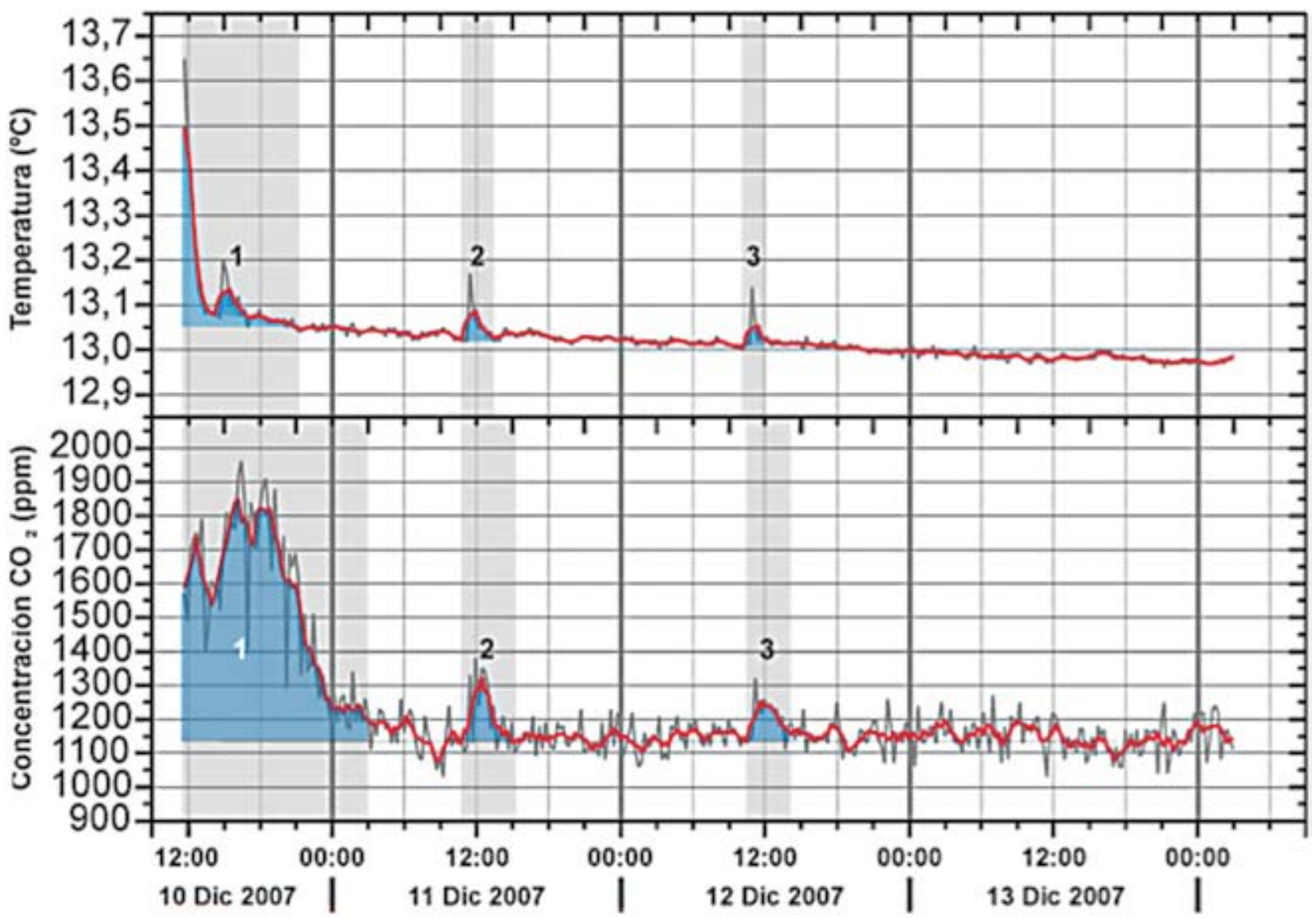

Fig. 23. Evolución de la concentración de $\mathrm{CO}_{2}$ y de temperatura en la Sala de las Pinturas en la Cueva de Praileaitz I para el periodo 10 a 14 de diciembre de 2007. La frecuencia de muestreo es de 15 minutos (línea gris). Se ha reflejado la media móvil (5 puntos) para cada serie de datos (línea roja). Se han indicado los periodos de influencia de las visitas en sombreado azul (Periodo 1,2 y 3 ). / Evolution of $\mathrm{CO}_{2}$ concentration and temperature in the Hall of Paintings in the Praileaitz Cave I during the period from 10 to 14 December 2007. The sampling frequency is 15 minutes (gray line). It has reflected the moving average (5 points) for each data series (red line). The blue shading zone indicates periods influenced by visits (Period 1, 2 and 3). 
medidas en continuo de la atmósfera subterránea cada 15 minutos desde el día 10 al 14 de diciembre de 2007. La humedad relativa ha permanecido siempre en saturación (100\%).

La primera observación sobre el funcionamiento de la cavidad, a partir de los datos disponibles (Fig. 23), es que hay una respuesta inmediata de la temperatura y concentración de $\mathrm{CO}_{2}$ del aire ante las visitas en la cueva, efectuadas los días 10, 11 y 12 de diciembre. La duración de la respuesta, así como su intensidad depende del número de personas y horas en las que permanezcan en la cueva. Se observa también que el tiempo necesario para que en la Sala de las Pinturas se restablezcan las condiciones naturales es siempre mayor para la concentración de $\mathrm{CO}_{2}$ que para la temperatura, lo que indica una mayor tasa de renovación energética del aire de la cavidad que de circulación del aire.

El periodo 1 (10 de diciembre de 2007) se caracteriza por la estancia continuada (5-6 horas) de tres investigadores en el interior de la cavidad, en el entorno de la Sala de las Pinturas. El acceso de los tres investigadores se realizó a las 11:00 horas. Tanto la temperatura como el $\mathrm{CO}_{2}$ registraron los mayores valores de la serie de datos y su efecto se mantuvo más tiempo, hasta las 21 horas del día 10 (temperatura) y 3 horas del día $11\left(\mathrm{CO}_{2}\right)$.

Los periodos 2 y 3 (11 y 12 de diciembre, respectivamente) se corresponden con visitas de menor duración de personal de la cantera de Praileaitz I para recoger datos del sismógrafo instalado en la misma Sala de las Pinturas. En estos dos periodos se pone de manifiesto que aunque la visita es de corta duración sus efectos permanecen varias horas después, aunque con menor duración que en el periodo 1. Del mismo modo que en el periodo 1, se observa que la recuperación en el $\mathrm{CO}_{2}$ se dilata más en el tiempo que la temperatura.

Se han realizado también cinco medidas puntuales de temperatura, humedad relativa y concentración de $\mathrm{CO}_{2}$ durante la campaña efectuada el día 10 de diciembre de 2007, cuatro en el interior y una de la atmósfera exterior (Tabl. 8). La medida de la atmósfera exterior se realizó a las 11:00 de la mañana.

\begin{tabular}{|l|c|c|c|}
\hline \multicolumn{1}{|c|}{ Toponimia } & \multicolumn{3}{|c|}{ AIRE } \\
\cline { 3 - 4 } & $\mathrm{CO}_{2}$ & Hum & $\mathrm{T}^{\mathrm{a}}$ \\
\hline Atmósfera exterior \\
\hline Sala Entrada \\
\hline Sala 1 \\
\hline Sala Pinturas \\
\hline Galeria Ascendente \\
\hline 500 & 90 & 10,0 \\
\hline 800 & 85 & 10,5 \\
\hline 1000 & 90 & 11,5 \\
\hline 1590 & 99 & 13,4 \\
\hline 1400 & 95 & 13,4 \\
\hline
\end{tabular}

Tabl. 8. Resultados de las medidas puntuales de temperatura humedad relativa y concentración de $\mathrm{CO}_{2}$ en la cueva de Praileaitz. Los valores se tomaron entre las 11:00 y las 13:00 horas del día 10 de diciembre de 2007. / Results of temperature, relative humidity and concentration of $\mathrm{CO}_{2}$ in the sampled points of Praileaitz cave I. The values were taken between 11:00 and 13:00 hours on December 10th, 2007.
La primera observación sobre el funcionamiento de la cavidad, a partir de los datos disponibles, es que se incrementan los valores de los parámetros registrados en comparación a los de la atmósfera exterior. Se produce un incremento progresivo desde la sala de entrada, hasta las salas más alejadas de la entrada actual.

Los valores de temperatura aumentan casi 3.5 grados en la sala de las pinturas y en los primeros metros de la galería ascendente. El aire de la cavidad en la Sala de las Pinturas alcanza su saturación en vapor de agua (99\% de humedad relativa) y el $\mathrm{CO}_{2}$ alcanza el máximo (1.600 ppm) en la Sala de las Pinturas.

Esta evolución es común para periodos invernales, ya que la temperatura exterior es inferior a la interior, la humedad del aire está saturada provocada por los constantes goteos que se producen en el interior de la cavidad y el $\mathrm{CO}_{2}$ del interior de la cavidad proviene, en su mayor parte, del alto $\mathrm{CO}_{2}$ generado por la degradación de la importante capa edáfica situada en el entorno.

Debido a que no se han realizado campañas antes de la puesta en marcha de la cantera, no se puede discernir si la explotación ha provocado cambios en las condiciones naturales de la cavidad. Serían necesarias series de datos de mayor longitud temporal para caracterizar la evolución de estos parámetros ambientales; sin embargo, cualquier cambio en éstos podría provocar una afección a las pinturas, tanto por el incremento de la temperatura del aire, la disminución de la humedad relativa, que conllevaría un resecado de las paredes de la cueva, y un cambio en el $\mathrm{CO}_{2}$, lo que provocaría modificaciones en el sistema calcocarbónico de las aguas de goteo y, por tanto, en las condiciones de disoluciónprecipitación de minerales carbonatados. Así, la construcción del camino justo encima de la cavidad, con el consiguiente desbroce de la flora y la desaparición de la capa edáfica -principal productora de $\mathrm{CO}_{2}-$ puede provocar cambios irreversibles.

\section{Resultado de parámetros hidroquímicos}

Durante la campaña del día 10 de diciembre se recogieron 4 muestras de agua, representativas del agua de infiltración de la cueva (Tabl. 9). Los puntos de muestreo se seleccionaron de los goteos más activos de la cavidad.

La mineralización de las aguas es media, con valores por encima de 320 microS/cm. Esta mineralización se debe a la actividad edáfica en superficie, donde la abundante materia orgánica en descomposición y, por tanto, alta producción de $\mathrm{CO}_{2}$ en el suelo, generan una importante disolución de la roca caliza.

Los pH son ligeramente básicos, con máximos en las salas más interiores de la cavidad, lo que demuestra mayor efecto tampón del sistema calcocarbónico.

Todas las aguas tienen facies bicarbonatadas cálcicas como se observa en el diagrama de Piper (Fig. 24). Esta composición química es la que cabe esperar por la litología carbonatada de la zona de estudio. 


\begin{tabular}{|c|c|c|c|c|c|c|c|c|c|c|c|c|c|c|}
\hline Toponimia & REF & CE & $T$ & $\mathrm{pH}$ & TOC & $\mathrm{Li}^{*}$ & $\mathrm{Na}^{+}$ & $\mathrm{K}^{*}$ & $\mathrm{Ca}^{2+}$ & $\mathrm{Mg}^{2+}$ & $\mathrm{HCO}_{3}{ }^{-}$ & $\mathrm{Cr}$ & $\mathrm{NO}_{3}{ }^{-}$ & $\mathrm{SO}_{4}{ }^{2-}$ \\
\hline Sala Entrada & 1 & 478 & 10,5 & 7,36 & 2,62 & - & 12,44 & 0,32 & 101,65 & 3,08 & 257,6 & 27,96 & 17,31 & 12,34 \\
\hline Sala 1 & 2 & 328 & 11,5 & 7,17 & 1,36 & - & 7,90 & 0,24 & 67,08 & 1,96 & 141,2 & 14,28 & 8,53 & 38,20 \\
\hline Sala Pinturas & 4 & 410 & 13.4 & 7.55 & 0,87 & 0.13 & 10,30 & 0,18 & 86,89 & 2.03 & 188,1 & 11,15 & 3.74 & 56,63 \\
\hline Galería Ascendente & 3 & 356 & 13.4 & 7.54 & 1,17 & - & 6.99 & 0.31 & 76,20 & 2,20 & 194,2 & 14,14 & 3.80 & 17,00 \\
\hline
\end{tabular}

Tabl. 9. Resultados analíticos de las muestras recogidas durante la campaña del 10 de diciembre de 2007. Leyenda, CE: conductividad eléctrica, T: temperatura, TOC: carbono orgánico total. Todos los parámetros en miligramos por litro, excepto $\mathrm{CE}$ en microS/cm y T en grados centígrados. / Analytical result of the collected samples during the campaign of December 10th, 2007. Legend, CE: electrical conductivity, T: temperature, TOC: Total organic carbon. All parameters are in milligrams per litre, except CE micros/cm and T in Celsius degrees.

En las aguas de los goteros de la cavidad predominan como anión y catión el bicarbonato y el calcio, con valores por encima de $140 \mathrm{mg} / \mathrm{L}$ y $65 \mathrm{mg} / \mathrm{L}$, respectivamente (Tabl. 9). Sin embargo, las concentraciones más altas se encuentran en los puntos de la entrada (punto 1), sala de las pinturas (punto 4) y galería ascendente (punto 3) donde las concentraciones de ambos iones están por encima de 180 y 75 mg/L (Fig. 24; Tabl. 9).

El gotero de la sala 1 (Fig. 25) muestra los valores más bajos de $\mathrm{CE}$ (328 microS/cm), $\mathrm{HCO}_{3}^{-}$(141,2 mg/L),
$\mathrm{Ca}^{2+}(67,08 \mathrm{mg} / \mathrm{L})$ y Mg${ }^{2+}(1,96 \mathrm{mg} / \mathrm{L})$ aun estando situado en una sala interior de la cavidad. Este hecho se debe a que el goteo del punto 2 está asociado a una importante fractura, lo que provoca que los flujos de infiltración sean más rápidos desde la superficie hasta la cavidad, disminuyendo el tiempo de contacto agua-roca y, por tanto, el efecto de disolución de la roca.

Es interesante observar que la concentración de sulfato presenta variaciones de más de $45 \mathrm{mg} / \mathrm{L}$, con valores de $12 \mathrm{mg} / \mathrm{L}$ en el punto 1 y de más de $55 \mathrm{mg} / \mathrm{L}$ en el

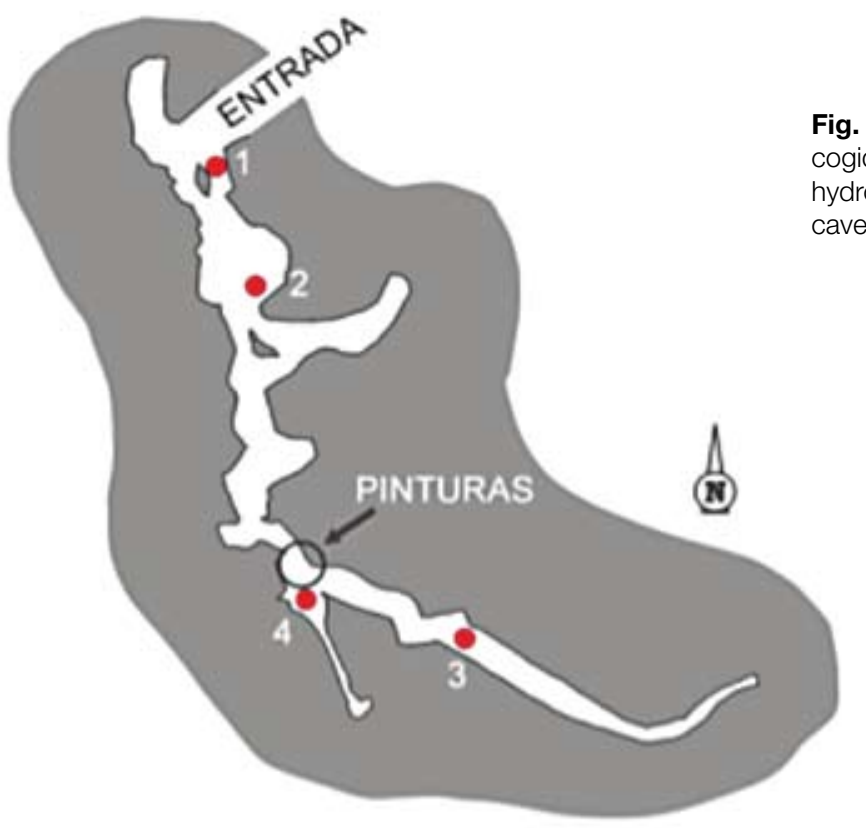

Fig. 24. Diagrama hidroquímico de Piper con las muestras de agua recogidas en la cueva de Praileaitz el día 10 de diciembre de 2007. / Piper hydrochemical diagram with water samples collected in the Praileaitz cave I on the 10th of December in 2007.

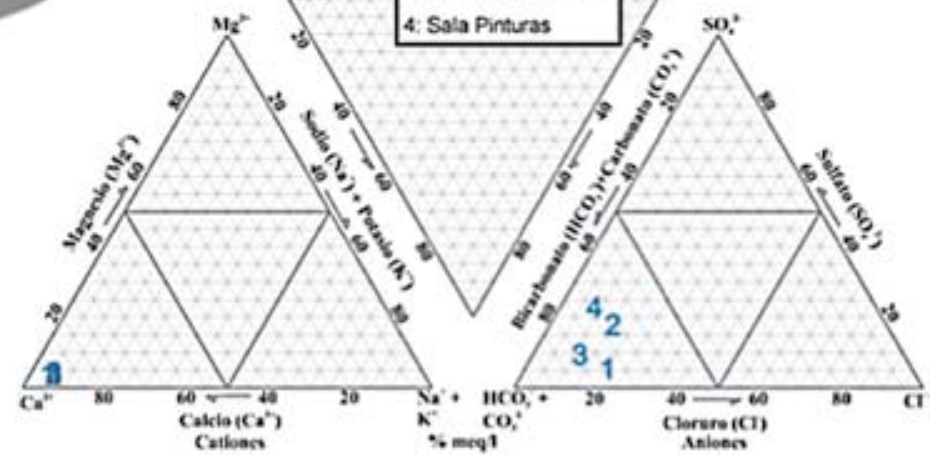



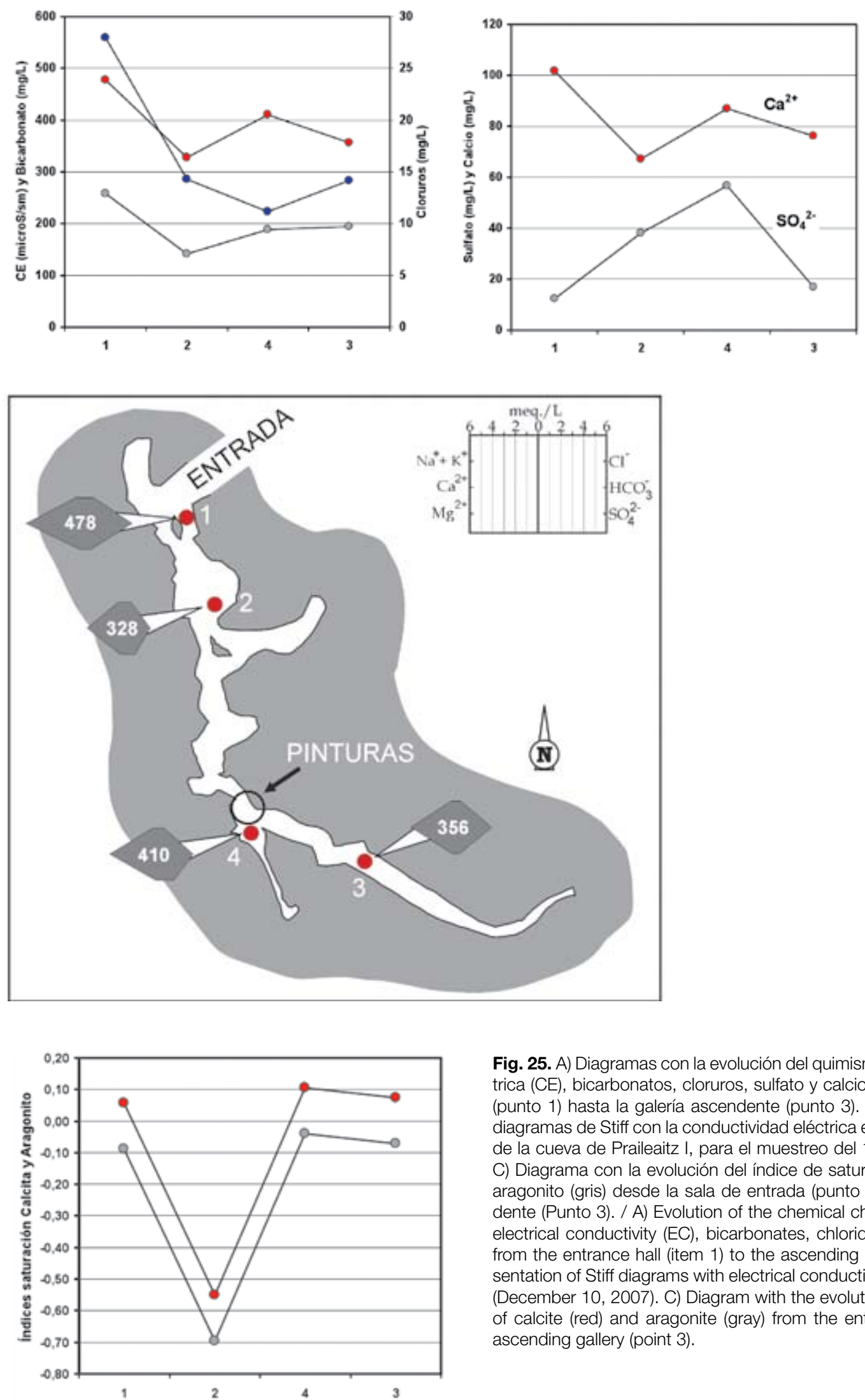

Fig. 25. A) Diagramas con la evolución del quimismo de conductividad eléctrica (CE), bicarbonatos, cloruros, sulfato y calcio desde la sala de entrada (punto 1) hasta la galería ascendente (punto 3). B) Representación de los diagramas de Stiff con la conductividad eléctrica en los puntos de muestreo de la cueva de Praileaitz I, para el muestreo del 10 de diciembre de 2007. C) Diagrama con la evolución del índice de saturación de la calcita (rojo) y aragonito (gris) desde la sala de entrada (punto 1) hasta la galería ascendente (Punto 3). / A) Evolution of the chemical characteristics derived from electrical conductivity (EC), bicarbonates, chlorides, sulphate and calcium from the entrance hall (item 1) to the ascending gallery (item 3). B) Representation of Stiff diagrams with electrical conductivity of the sampling points (December 10, 2007). C) Diagram with the evolution of the saturation index of calcite (red) and aragonite (gray) from the entrance hall (item 1) to the ascending gallery (point 3). 
punto 4 (Sala de las Pinturas). Las concentraciones por encima de $35 \mathrm{mg} / \mathrm{L}$ de $\mathrm{SO}_{4}{ }^{2-}$ son más altas de lo que cabría esperar en un sistema con una litología carbonatada, por lo que debe existir otras posibles fuentes de sulfato, además de la reconcentración del agua de lluvia. Las dos posibles fuentes de sulfato en la roca de caja de la región son (1) la presencia de diseminados de minerales evaporíticos (yeso: $\mathrm{CaSO}_{4}$ ) y (2) diseminados de sulfuros metálicos (Metal-S), que al oxidarse el sulfuro generarían sulfatos en el agua. En ambos casos, discernir el origen es difícil sin realizar otros análisis hidrogeoquímicos e isotópicos de ${ }^{34} \mathrm{~S}$ del sulfato en el agua, aspecto que se sale del objetivo de la presente investigación. A tenor de la geología del entorno, sin embargo, todo apunta a que pueda derivar del contenido en pirita de la caliza urgoniana.

Uno de los aspectos hidrogeoquímicos más importantes que cabe considerar en la presente investigación es comprobar el estado de saturación del agua de los goteos en minerales carbonatados (calcita y aragonito). Dicho estado es crucial para comprobar si las aguas son agresivas (índice de saturación por debajo de cero: conservan la capacidad para disolver la roca carbonatada) o incrustantes (índice de saturación por encima de cero: capacidad para precipitar mineral carbonatado). Un cambio en este estado de saturación, inducido por cualquier modificación antrópica de las condiciones de infiltración del agua, podría provocar disolución de la roca carbonatada, y con ello la desaparición de las pinturas, o por el contrario precipitación de minerales carbonatados por encima de la superficie actual.

Se han modelizado hidrogeoquímicamente las cuatro muestras de aguas de goteo y se han calculado automáticamente los índices de saturación para la calcita y el aragonito (Tabl. 10), los minerales más comunes en los espeleotemas en cavidades. Para el cálculo del índice de saturación se ha utilizado el código hidrogeoquímico EQ3, que ha permitido calcular el índice de saturación de decenas de minerales, de entre los cuales se han extraído los dos de interés para esta investigación.

Se puede observar que, en general, las aguas están cercanas al equilibrio en calcita y ligeramente subsaturadas en aragonito. Sólo en el punto 2 (Sala 1) se observa una gran subsaturación en ambos minerales (Tabl. 10 y

\begin{tabular}{|c|c|}
\hline Toponimia & REF \\
\hline Sala Entrada & 1 \\
\hline Sala 1 & 2 \\
\hline Sala Pinturas & 4 \\
\hline Galeria Ascendente & 3 \\
\hline
\end{tabular}

\begin{tabular}{|c|c|}
\hline \multicolumn{2}{|c|}{ Indices de saturación } \\
\hline Calcita & Aragonito \\
\hline 0,057 & $-0,088$ \\
\hline$-0,551$ & $-0,696$ \\
\hline 0,105 & $-0,040$ \\
\hline 0,073 & $-0,072$ \\
\hline
\end{tabular}

Tabl. 10. Índices de saturación calcita y aragonito de las muestras de agua de goteos recogidas el día 10 de diciembre de 2007 en la cueva de Praileaitz I. / Calcite and aragonite Saturation Index of the water samples from drippings collected on December 10th, 2007.
Fig. 25), lo que está provocado por el tránsito rápido del agua de infiltración por esa zona de fractura, lo que permite que al agua no le dé tiempo a disolver los minerales carbonatados de la roca.

Este aspecto es muy importante en este entorno, ya que la construcción del camino justo por encima de la cavidad puede provocar que el agua que antes se infiltraba y se equilibraba en calcita y aragonito, llegue a la cavidad en estado de subsaturación en ambos minerales y tienda a disolver la roca y, con ella, las manifestaciones pictóricas de la sala de las pinturas.

\section{5.-CONCLUSIONES}

El entorno geomorfológico de la cuenca baja del río Deba obedece a un modelado kárstico de zonas húmedas tropicales, tipo "Cockpits", con desarrollo de grandes depresiones irregulares (dolinas) a partir de superficies fundamentales planares localizadas en torno a los $150 \mathrm{~m}$ de altitud y relieves positivos cónicos (no erosivos).

En la cueva de Praileaitz I se distinguen 3 zonas distintas, tanto desde el punto de vista geomorfológico como del relleno sedimentario:

a) La entrada, dominada por la sima vertical, con un desarrollo profuso de espeleotemas de tipo cascada y estalagmitas, fosilizadas y parcialmente enterradas por derrubios detríticos procedentes del suelo exterior y éboulis de la propia caliza.

b) Desde la entrada hasta la antesala de las pinturas (salas norte, primera sala interna, segunda sala interna y la gatera): desarrollo subhorizontal con techos muy abovedados a 1,10 del suelo encostrado, salas subcirculares e importante entrada de sedimento por la sala 2.

c) Desde la sala de las pinturas hasta el final de la galería ascendente, destaca un mayor desarrollo de las cuevas en la vertical (modelado vadoso ¿?), mostrando una sección más ovalada y la fuerte inclinación ascendente del techo galería arriba. El sedimento que aflora en superficie, fruto de la infiltración de un suelo inmaduro y lleno de caracoles no fosilizados y carbones, podría obedecer a un aporte sedimentario reciente en tiempo (¿histórico?).

El tipo de sedimento que abunda en la cueva de Prailaitz I es de tipo detrítico alóctono (procedente, en mayor parte, desde el exterior) y relacionado con suelos generados en rocas siliciclásticas (no carbonatadas), alternando con la formación de sedimentos químicos (espeleotemas).

El sedimento procede del lavado del suelo siliciclástico que un tiempo atrás pudo existir en la vertical de las calizas (no de suelos generados en calizas) o ha sido transportado desde las inmediaciones siliciclásticas, tal y como atestiguan los cantos centimétricos de limonita, cuarcita blanca, fragmentos de arenisca, entre otros, y la mineralogía de las arcillas. 


\section{MAPA GEOMORFOLÓGICO DE PRAILEAITZ}

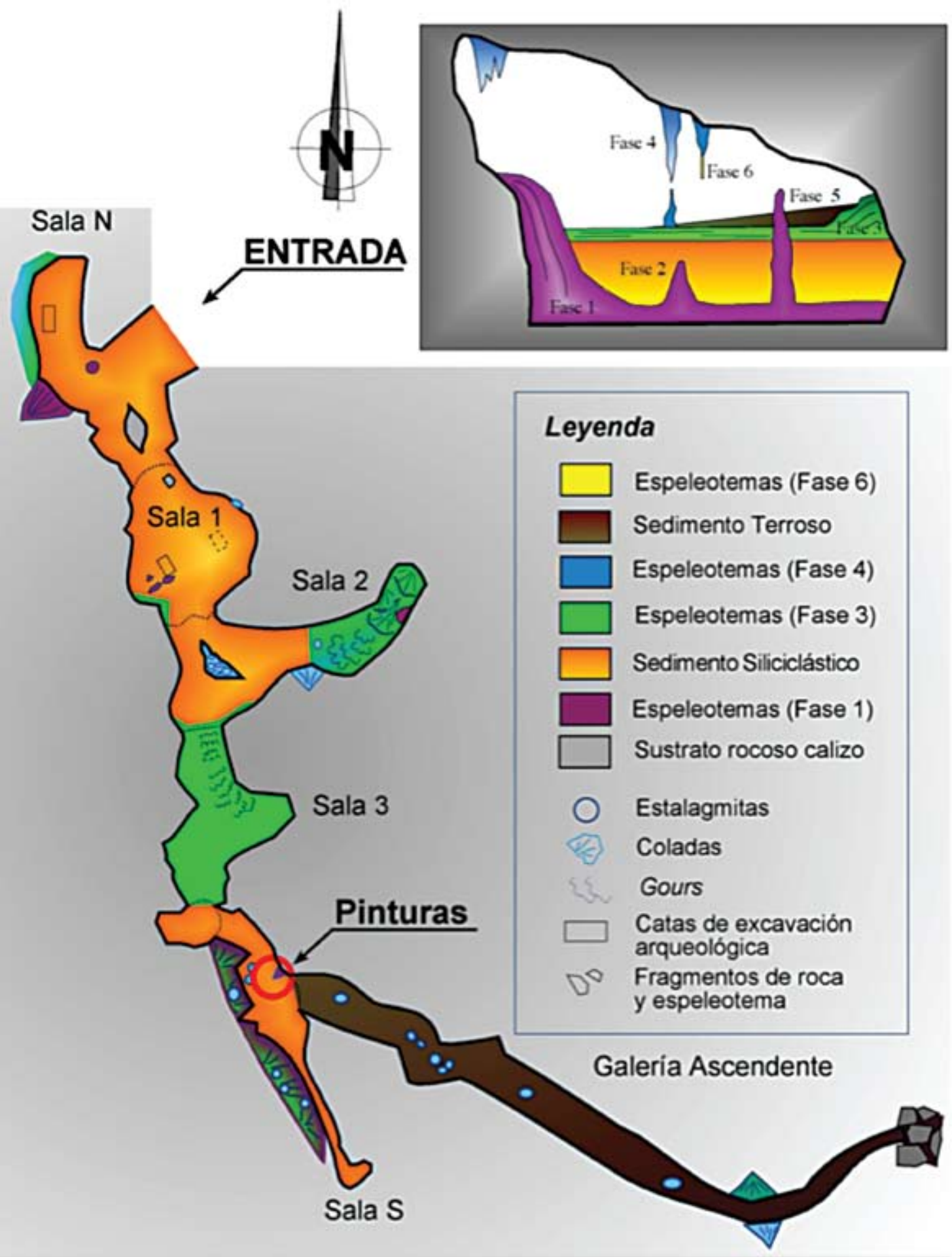

Fig. 26. Mapa geomorfológico de Praileaitz I con las distintas fases de formación y relleno. / Geomorphological map of Praileaitz cave with the different formation and sedimentary stages. 
El aporte sedimentario ha sido homogéneo, en cuanto a su naturaleza, a lo largo de la estratigrafía de las catas arqueológicas estudiadas.

Los análisis sedimentológicos que se han realizado en el sedimento arqueológico confirman una matriz del relleno muy homogénea con materiales predominantemente finos aportados por escorrentía a partir del lapiaz o lenar. Se observan momentos de mayor energía pero en general ha sido suave. Es notable la presencia de gránulos ferruginosos entre estos materiales. Sólo en algunos niveles se encuentran fracciones gruesas con fragmentos de espeleotemas y calizas.

La galería ascendente presenta un último relleno subactual caracterizado por abundantes fragmentos de carbón, hojas, caracoles no fosilizados, ausencia de cantos de limonita y abundancia relativa de la vermiculita (filosilicato), indicando un suelo maduro kárstico como área fuente y/o transportado desde el exterior.

La existencia de depósitos gravitacionales relacionados con cambios de temperatura (éboulis) en las cercanías de la entrada actual hace pensar que ha sido ésta la zona más abierta de la cueva.

Se han descrito 4 estadios de formación de espeleotemas a lo largo de la cavidad, pero destaca el grado de deterioro de los mismos, debido quizás a procesos químicos de corrosión, como por la actividad orgánica (microrganismos, raíces y bioturbaciones).

La evolución de la cueva podría articularse en torno a seis eventos principales (a falta de conocer más estratigrafía de relleno) (Fig. 26):

- La formación de la galería en condiciones freáticas y en relación al encajamiento del nivel de base (Fase 0 o formación de la cavidad) (Pleistoceno inferior-medio?). Durante este periodo el sistema fluvial podría encontrarse a la misma cota (ARRIOLABENGOA, 2015).

- Un primer relleno, ya en condiciones vadosas, de carácter químico (espeleotemas, Fase 1), formado entre >350-112 ka, aproximadamente.

- Relleno detrítico (Fase 2) a través de varias entradas a la cueva (entrada, segunda sala interior, sala norte, sala sur) y ocupación de la cavidad por los humanos y otros vertebrados antes y durante el Solutrense - Magdaleniense (17.000 a. ¿?).

- Sellado de toda la cueva por espeleotemas laminares (costra de 10-15 cm con gours y cascadas en algunas entradas, Fase 3) y proliferación de espeleotemas de goteo encima del espeleotema laminar a lo largo de toda la cueva (Fase 4) durante el Holoceno.

- Infiltración de suelo a través del lapiaz en la galería ascendente en época más reciente, desde el extremo SE de la propia galería (zona de colapso de bloques) (Fase 5).

- Formación actual de espeleotemas (Fase 6).
Esta campaña ha permitido disponer de los primeros resultados hidroquímicos y ambientales de la cavidad. Sin embargo, una sola campaña de muestreo no permite establecer comparativas entre la situación con anterioridad a la explotación de la cantera y la situación actual.

Se observa que tras la visita del personal investigador a la galería de las pinturas, los parámetros ambientales varían (Fig. 23), y la recuperación del $\mathrm{CO}_{2}$ se dilata más en el tiempo que la temperatura, lo que indica una mayor tasa de renovación energética del aire de la cavidad que de circulación del aire. Es por tanto, imprescindible realizar un estudio exhaustivo de las variaciones de los parámetros ambientales para comprobar la influencia de las actividades humanas en el interior de la cueva y la capacidad de recuperación de la misma.

\section{6.- AGRADECIMIENTOS}

Este trabajo forma parte del "Estudio Geológico del entorno de la cavidad de Praileaitz I (Deba, Gipuzkoa)" realizado para la Sociedad de Ciencias Aranzadi por encargo de la Diputación Foral de Gipuzkoa. Queremos agradecer a Carlos Olaetxea por toda la ayuda prestada, a los revisores por mejorar el contenido de esta aportación científica así como a los editores. Así mismo, quisiéramos agradecer a Javier Sangüesa Aguerri, técnico del Servicio de DRX: Rocas y Minerales, de Servicios Generales de Investigación SGlker de la UPV/EHU por las labores realizadas y a lo técnicos de laboratorio de la Universidad de Málaga. Parte de esta investigación ha sido realizada al amparo del Proyecto de Investigación UPV/EHU11/21 y la UFI11/09.

\section{7.- BIBLIOGRAFÍA}

\section{AGUIRREZABALA, L.M.}

1996 El Aptiense-Albiense del Anticlinorio Nor-Vizcaino entre Gernika y Azpeitia. Tesis Doctoral inédita. EHU/UPV. 429 pp,

ARANBURU, A., ARRIOLABENGOA, M., IRIARTE, E., GIRALT, S., YUSTA, I., MARTÍNEZ-PILLADO, V., DEL VAL, M., MORENO, J., JIMÉNEZ-SÁNCHEZ, M.

2015 Karst landscape evolution in the littoral area of the Bay of Biscay (north Iberian Peninsula). Quaternary International 364, 217-230. doi:10.1016/j.quaint.2014.09.025.

ARRIOLABENGOA, M.; GARZÓN, G.; ARANBURU, A.; IRIARTE, E.

2012 Correlación de discontinuidades entre diferentes unidades geomorfológicas en los macizos kársticos de Arno e lzarraitz (Gipuzkoa), en: GONZÁLEZ-DÍEZ, A., FÉRNÁNDEZ-MAROTO, G., DOUGHTY, N.W., REMONDO, J., BRUSCH, V.M., BONACHEA, J., DÍAZ DE TERÁN, J.R., MARTÍNEZCEDRÚN, P., RNAS, V., FLOR, G., SERRANO, E., GUTIERREZ-SANTOLALA, F., BENITO, G., DESIR, G., LÓPEZ, J., ROMERO, M.A., BATALA, R., GARCÍA-PRIETO, F.J., FLOR-BLANCO, G., GARZÓN, G., CARDENAL, J., VLAPLANA, J.M., COROMINAS, J., DIAZZ-MARTÍNEZ, E., JIMÉNEZ-SÁNCHEZ, M. \& GUERRA, J.C. (Eds). Avances de la geomorfología en España 2010-2012. Santander, 393-396. 
ARRIOLABENGOA, M.

2015 Evolución geológica cuaternaria del valle del río Deba (Gipuzkoa). Tesis Doctoral inédita, UPV/EHU. 196 pp.

ARRIOLABENGOA, M., IRIARTE, E., ARANBURU, A., YUSTA, I., ARRIZABALAGA, A.

2015 Provenance study of endokarst fine sediments through mineralogical and geochemical data (Lezetxiki II cave, northern Iberia). Quaternary International 364, 231-243. doi:10.1016/j.quaint.2014.09.072.

CHIANG, HC., CHEN, ZS., HSEU, ZY.

1997 Micromorphology of iron nodules in a montane Ultisols of central Taiwan. J. Taiwan Sci 12, 413-420.

DURÁN, J. J.; VALLEJO, M.; LÓPEZ-MARTíNEZ, J.

2000 Propuesta de una clasificación de espeleotemas. Geotems 1(3), 337-340.

E.V.E.

2003 Mapa Geológico del País Vasco 1:25.000. CD, Ente Vasco de la Energía.

GILLIENSON, D.

1996 Caves: Processes, Development and Management. Blackwell. Oxford.

HERNANDO MASSANET, I.; HERNANDO COSTA, J.; BARBA CARRETERO, A.; BARBA SOLANA, C.

2001 Vermiculita en Suelos Desarrollados sobre Gneis. Edafología 8, 9-19.

IRIARTE E., SÁNCHEZ M.A., FOYO A. Y TOMILLO C.

2010 Geological risk assessment for cultural heritage conservation in karstic caves. Journal of Cultural Heritage 11, 250-258.

LAVILLE, H.

1975 Climatologie et chronologie du Paléolithique en Périgord: étude sédimentologique de dépôts en grotte et sous abris. Etudes Quaternaires 4.
LAVILLE, H.; RIGAUD, J-P.; SACKEIT, J.

1980 Rock Shelters of the Perigord. Academic Press, New York.

MISKOVSKY, J.C.

1974 Le quaternaire du Midi Méditerranéen. Stratigraphie et Paléoclimatologie d'après l'étude sédimentologique du remplissage des grottes et abris sous roches. Etudes Quaternaires 3.

MISKOVSKY, J.C (ED.)

1987 Géologie de la préhistoire: méthodes, techniques, applications. Association pour l'Étude de l'Environnement Géologique de la Préhistoire. GEOPRÉ. Paris.

MOORE, D.M. Y REYNOLDS, R.C.

1997 X-Ray Diffraction and the Identification and Analysis of Clay Minerals, 2nd ed. Oxford University Press. Oxford New York.

REID, R. P.; MACINTYRE, I. G.

1998 Journal of Sedimentary Research 68, 928-946 Part A.

SCHULTZ, L.G.

1964 Quatitative interpretation of mineralogical composition from X-ray and chemical data for the Pierre Shale.U.S Geological Survey Professional Paper, 391-C.

SWEETING, M.M

1995 Karst in China: its Geomorphology and Environment. Springer-Verlag. Berlin.

VANGHI, V., IRIARTE, E., ARANBURU, A.

2015 High resolution X-ray computed tomography for petrological characterization of speleothems. Journal of Cave and Karst Studies 77-1, 75-82.

WILLIAMS, P.W.

1971 Illustrating morphometric análisis of karst with examples from New Guinea. Zeitschrift für Geomorphologie 15, 40-61.

1972 Morphometric análisis of poligonal karst in New Guinea. Geological society of America Bulletin 83, 761-796. 
